\title{
The 100-plus Study of cognitively healthy centenarians: rationale, design and cohort description
}

\author{
Henne Holstege $\mathrm{e}^{1,2}$ (1) $\cdot$ Nina Beker $^{1} \cdot$ Tjitske Dijkstra $^{1} \cdot$ Karlijn Pieterse $^{1} \cdot$ Elizabeth Wemmenhove $^{1} \cdot$ \\ Kimja Schouten ${ }^{2} \cdot$ Linette Thiessens $^{1} \cdot$ Debbie Horsten $^{1} \cdot$ Sterre Rechtuijt ${ }^{1} \cdot$ Sietske Sikkes $^{1}$ • \\ Frans W. A. van Poppel ${ }^{3} \cdot$ Hanne Meijers-Heijboer $^{2} \cdot$ Marc Hulsman $^{1,2} \cdot$ Philip Scheltens $^{1}$
}

Received: 7 April 2018/ Accepted: 3 October 2018/Published online: 25 October 2018

(C) The Author(s) 2018

\begin{abstract}
Although the incidence of dementia increases exponentially with age, some individuals reach more than 100 years with fully retained cognitive abilities. To identify the characteristics associated with the escape or delay of cognitive decline, we initiated the 100-plus Study (www.100plus.nl). The 100-plus Study is an on-going prospective cohort study of Dutch centenarians who self-reported to be cognitively healthy, their first-degree family members and their respective partners. We collect demographics, life history, medical history, genealogy, neuropsychological data and blood samples. Centenarians are followed annually until death. PET-MRI scans and feces donation are optional. Almost $30 \%$ of the centenarians agreed to post-mortem brain donation. To date (September 2018), 332 centenarians were included in the study. We analyzed demographic statistics of the first 300 centenarians (25\% males) included in the cohort. Centenarians came from higher socio-economic classes and had higher levels of education compared to their birth cohort; alcohol consumption of centenarians was similar, and most males smoked during their lifetime. At baseline, the centenarians had a median MMSE score of 25 points (IQR 22.0-27.5); most centenarians lived independently, retained hearing and vision abilities and were independently mobile. Mortality was associated with cognitive functioning: centenarians with a baseline MMSE score $\geq 26$ points had a mortality percentage of $17 \%$ per annual year in the second year after baseline, while centenarians with a baseline MMSE score $<26$ points had a mortality of $42 \%$ per annual year $(p=0.003)$. The cohort was 2.1 -fold enriched with the neuroprotective $A P O E-\varepsilon 2$ allele relative to 60-80 year-old population controls $\left(p=4.8 \times 10^{-7}\right), A P O E-\varepsilon 3$ was unchanged and the $A P O E-\varepsilon 4$ allele was 2.3-fold depleted $\left(p=6.3 \times 10^{-7}\right)$. Comprehensive characterization of the 100 -plus cohort of cognitively healthy centenarians might reveal protective factors that explain the physiology of long-term preserved cognitive health.
\end{abstract}

Keywords 100-plus Study $\cdot$ Prospective cohort study $\cdot$ Centenarians $\cdot$ Cognitive health longevity

\section{Background}

Electronic supplementary material The online version of this article (https://doi.org/10.1007/s10654-018-0451-3) contains supplementary material, which is available to authorized users.

Henne Holstege

h.holstege@vumc.nl

1 Alzheimer Center Amsterdam, Department of Neurology, Amsterdam Neuroscience, Vrije Universiteit Amsterdam, Amsterdam UMC, de Boelelaan 1118, 1081 HZ Amsterdam, The Netherlands
Although increasing age is the strongest risk indicator for cognitive decline and dementia, it is not an inevitable consequence of aging. The incidence of overall

Department of Clinical Genetics, Amsterdam Neuroscience, Vrije Universiteit Amsterdam, Amsterdam UMC, de Boelelaan 1118, 1081 HZ Amsterdam, The Netherlands

3 Netherlands Interdisciplinary Demographic Institute (NIDI/ KNAW), Lange Houtstraat 19, 2511 CV The Hague, The Netherlands 
dementia starts to increase exponentially from approximately 60 years and at age 100 years the annual dementia incidence reaches $40 \%$ per year [1, 2]. However, the mere existence of cognitively healthy individuals older than 110 years [3-6] leads to the intriguing suggestion that the incidence of dementia decelerates somewhere after 100 years (see Box). Factors that allow for the preservation of cognitive health may thus be enriched for in super-agers, individuals who reach extreme ages with full cognitive functions [7]. The combination of extreme old age with maintained cognitive health is often observed in families [8-13], suggesting that beneficial factors involved in the long-term maintenance of both cognitive and overall health are heritable, and likely genetic [7, 14-16]. Indeed, results from the New England Centenarian Study indicated that siblings from centenarians are $\sim 8-12$ times more likely to reach 100 years compared to individuals with no centenarian siblings [17].

This raises several questions: what are the unique molecular mechanisms that cause resilience against age related decline? Which hereditable factors are involved, and what is the role of the immune system? The answers to these questions are likely to provide novel insights in the effects of aging on the brain and they will be informative for the design of novel strategies that intervene in processes that lead to neurodegenerative diseases [18]. Answers to these questions might be found in the context of prospective follow-up studies, however, this is complicated by the fact that only $\sim 0.6 \%$ of the population born in the early 1900s reaches 100 years (see Box). Therefore, we set out to identify protective factors in a cohort of centenarians who self reported to be cognitively healthy. For this, we initiated the 100-plus Study in 2013 at the Alzheimer Center Amsterdam in the Netherlands (www.100plus.nl). To date, the cohort includes 332 centenarians.

Children of centenarians also profit from the advantage they inherited from their centenarian parent: they live longer, and they have almost a 90\% lower risk of developing myocardial infarction, stroke and diabetes compared to age-matched peers whose parents have average life spans $[15,19,20]$. Together, this suggests that first-degree family-members of centenarians are also enriched for protective (genetic) factors and that efforts to identify protective factors should include targeting the families of centenarians [21]. The value of using by-proxy phenotypes for genetic studies was recently demonstrated for 12 diseases [22], and recently for Alzheimer's Disease [23, 24]. Centenarian children represent the by-proxy phenotype of extreme longevity which allows the opportunity to compare the composition of biomaterials or other features relative to age-matched controls [25]. For this reason, we extended the 100-plus Study with a second phase in 2017, in which we also include first-degree family-members of centenarians and their partners.

The 100-plus Study has a main focus on the biomolecular aspect of preserved cognitive health. It is beneficial that cohort inclusion is on-going, as this allows us to take optimal advantage of the recent developments in highthroughput biomolecular techniques. For example, genetic variants of interest can be functionally tested in our collection of fresh blood samples and brain tissues from carriers.

Here we present the rationale for the 100-plus Study (see Box), we describe the study design and procedures, and we introduce the 100-plus Study cohort based on the clinical presentation of the centenarians at baseline, and the demographic characteristics of the centenarians relative to their birth cohort.

\section{Methods/study design}

Please find in the electronic supplementary material (ESM.pdf) a complete compendium of participant inclusion procedures and current data collection procedures of the 100-plus Study.

\section{Inclusion and exclusion criteria}

The 100-plus Study includes (1) Dutch-speaking centenarians who can (2) provide official evidence for being aged 100 years or older, (3) self-report to be cognitively healthy, which is confirmed by an informant (i.e. a child or close relation), (4) consent to donation of a blood sample and (5) consent to (at least) two home-visits from a researcher, which includes an interview and neuropsychological testing. In the second phase of the 100-plus Study (from September 2017 onwards) we include (1) siblings or children from centenarians who participate in the 100-plus Study, or partners thereof who (2) agree to donate a blood sample, (3) agree to fill in a family history, lifestyle history and disease history questionnaire. Study exclusion criteria are limited to subjects who are legally incapable.

\section{Recruitment and research visits}

\section{Recruitment}

We regularly perform an online search for local newspaper articles that mention a centenarian. These reports commonly include the name of the centenarian, and sometimes a description of their well-being and living situation. We retrieve an address online and we approach a prospective study participant by letter. When they express their interest in study participation and inclusion criteria are met, we 
schedule two baseline visits. (See ESM.pdf for detailed recruitment procedures).

\section{Baseline visit}

A researcher, trained to perform standardized visit procedures, will visit the centenarian. The baseline visit (T0) consists of two visits. The first baseline visit takes approximately 2 to $3 \mathrm{~h}$, and comprises obtaining informed consent for study inclusion, a life-history interview, an assessment of genealogy, and an assessment of current health and medical history (Table 1). The second baseline visit, approximately 1 week after the first, takes approximately $1.5 \mathrm{~h}$ : during this visit we subject the centenarian to a battery of neuropsychological tests and we measure grip strength and blood pressure (Table 2). During the first baseline visit we inform participants of optional parts of the 100-plus Study: feces collection, PET-MRI or PET-CT imaging and post-mortem brain donation (Fig. 1). Once a centenarian volunteers to participate in these parts of the 100-plus Study, we obtain informed consent for these study parts separately.

\section{Follow-up visits}

During yearly follow-up visits $(\mathrm{T} 1, \mathrm{~T} 2, \ldots)$, which take approximately $2 \mathrm{~h}$, we inform about possible changes in cognitive functioning that took place in the last year, we update the interview questionnaire and re-administer the complete cognitive test battery and physical measurements (Tables 1, 2). Follow-up is continued until the participant is no longer willing/able to participate. When the MMSE score declines $\leq 20$ there is evidence of clear cognitive impairment [26], and subjecting a centenarian to a neuropsychological testing battery becomes more complicated and follow-up visits by a researcher may no longer be constructive. When the MMSE at last visit drops below 20 (imputed MMSE score), we follow-up by informant questionnaire. To ensure up-to-date cognitive health measurements of brain donors, we administer telephone an informant questionnaires 6 months after the annual visit (T0.5, T1.5, ...). For a diagram of procedures see Fig. 2. We ask informants to inform us when a participant dies and about the events that preceded death.

\section{Data collection}

\section{Centenarian presentation}

During each visit, the researcher subjectively estimates the visual, hearing and mobility function as "good", "moderate", "poor" or "very poor", according to the determinants listed in Table 3. We collect the following variables regarding centenarian presentation: the level of independence during activities of daily living (ADL) using the Barthel Index [27], an estimation of the total hours of care/ assistance needed per week; category housing situation, (independent-dependent); grip strength, systolic and diastolic blood pressure; heartbeat; and napping habits and sleep quality (Pittsburg Sleep Quality Index questionnaire [28]). We assess whether the centenarian suffers from symptoms of depression [29] by administering the 15-item geriatric depression scale (GDS-15). We ask about recent weight loss, current weight and length and whether the centenarian has active infections.

\section{Medical history}

From the General Practitioner (GP) of the centenarian, we request a summary report of the diagnosed conditions and prescribed medications. These conditions are categorized by a GP dedicated to the 100-plus Study (Table 4). After a centenarian dies, we request a second synopsis from the GP, describing the medical proceedings until death. In a self-report medical history questionnaire, we inquire about blood pressure, heart disease; stroke (CVA) or TIA; tumors, head injuries, incontinence, dental condition, mental health problems, hospital visits, surgeries/anesthesia. We estimate BMI at midlife by recording self-reported weight and length at middle-age ( $\sim 50$ years). For centenarian-females we inquire about age at menarche, onset of menopause, number of pregnancies and/or miscarriages.

\section{Cognitive profiling}

We objectively evaluate cognitive functioning using a comprehensive neuropsychological test battery that addresses memory, attention and/or concentration, premorbid intelligence, language, executive and visuo-spatial functions (Table 2). To assess overall cognitive functioning we administer the Mini-Mental State Examination (MMSE) [26]. Geriatric sensory impairments such as bad eyesight or bad hearing complicated performance, which led to missing items. MMSE scores with different missing items cannot be directly compared, because the total obtainable score is different per centenarian. Therefore, we adjust scores using multiple imputation (see 'MMSE imputation' in ESM.pdf). In addition, at every visit the researcher subjectively estimated cognitive functioning of the centenarian (for procedures see ESM.pdf). During each research visit we ask an informant to fill in the Dutch version of the abbreviated form of the Informant Questionnaire on Cognitive Decline (IQ-CODE) to indicate whether the centenarians experienced cognitive decline in the past 10 years (or, in case of follow-up visits, during the past year) [30, 31]. 
Table 1 Overview of 100-plus Study data-collection

\begin{tabular}{|c|c|}
\hline Study participants & Actions \\
\hline \multirow{25}{*}{$\begin{array}{l}\text { Centenarians } \\
\text { Phase } 1 \text { and Phase } 2\end{array}$} & First baseline visit: interview \\
\hline & Formalities for study inclusion: ICF; Proof of age \\
\hline & $\begin{array}{l}\text { Childhood living environment; Education; Marriage/Partners; Number of children, Religion, Occupation; Occupation } \\
\text { of parents and partner }\end{array}$ \\
\hline & Genealogy of first degree family members and partners; Disease history in family \\
\hline & Lifestyle Questionnaire: Smoking habits; Drinking habits; Lifetime cognitive activity scale; situation during WWII \\
\hline & $\begin{array}{l}\text { Disease history (self-report): weight/length; incontinence; medication intake, dental condition (stopped); hospital visits/ } \\
\text { anesthesia }\end{array}$ \\
\hline & Researcher subjective estimate of sight, hearing, mobility, cognitive status; \\
\hline & $\begin{array}{l}\text { Centenarian presentation: current housing situation, total hours of care; ADL (Barthel index); sleep quality (PSQI); } \\
\text { Geriatric Depression Scale (GDS); cognitive well-being judged by informant (IQ-CODE) }\end{array}$ \\
\hline & Collection of biomaterials and biomarkers: blood sample ${ }^{\mathrm{ab}}$ \\
\hline & Second baseline visit \\
\hline & Neuropsychological test battery: Table 2 \\
\hline & Measurement of grip strength ${ }^{b}$ and blood pressure ${ }^{b}$ \\
\hline & Follow up \\
\hline & $\begin{array}{l}\text { MMSE at last visit > 20: yearly visit: update of general well-being, disease history, and missed items at baseline } \\
\text { interview; Researcher subjective estimate of sight, hearing, mobility, cognitive status; }\end{array}$ \\
\hline & $\begin{array}{l}\text { Neuropsychological testing battery (Table 2) Barthel index; GDS; IQ-CODE, grip strength measurement }{ }^{\mathrm{b}} \text {; blood } \\
\text { pressure measurement }^{\mathrm{b}}\end{array}$ \\
\hline & $\begin{array}{l}\text { MMSE at last visit } \leq 20 \text {; phone interview: update of general well-being, disease history, and missed items at baseline } \\
\text { interview; IQ-CODE (by mail), ADL (Barthel index) }\end{array}$ \\
\hline & For brain donors: half yearly follow-up: TICs-M (by telephone); IQ-CODE (by mail) \\
\hline & GP \\
\hline & At baseline inclusion: request for summary of medical events \\
\hline & Post mortem: request medical events leading to death \\
\hline & Optional in Phase-2 \\
\hline & MRI-PET or PET-CT scan \\
\hline & Feces donation \\
\hline & iPS cell generation \\
\hline & Post mortem brain donation \\
\hline \multirow{8}{*}{$\begin{array}{l}\text { Centenarian children and partners } \\
\text { Phase-2 }\end{array}$} & Baseline visit \\
\hline & Formalities for study inclusion: ICF \\
\hline & Collection of blood sample ${ }^{b}$ \\
\hline & Mail: Questionnaire on lifestyle, general well-being, education and occupation, disease history and genealogy \\
\hline & Follow up \\
\hline & No follow-up \\
\hline & GP \\
\hline & For specific cases: request for summary of medical events \\
\hline \multirow{2}{*}{$\begin{array}{l}\text { Centenarian-siblings and partners, } \\
\text { centenarian-partners }\end{array}$} & Baseline visit \\
\hline & Update lifestyle questionnaire, current health, disease history and general well-being Blood sample, MMSE, Barthel \\
\hline \multirow{6}{*}{ Phase-2 } & index; IQ-CODE; grip strength ${ }^{\mathrm{b}}$ and blood pressure measurement, ${ }^{\mathrm{b}}$ estimation of sight, hearing, and mobility; \\
\hline & Researcher subjective estimate of sight, hearing, mobility, cognitive status; \\
\hline & Mail: questionnaire on lifestyle, general well-being, education and occupation, disease history, and genealogy \\
\hline & Follow up \\
\hline & Yearly: TICs-M (by telephone); IQ-CODE (by mail) \\
\hline & GP \\
\hline
\end{tabular}

${ }^{a}$ Blood sample collection may occur at a different occasion, close to first baseline visit; Phase-2 of the 100-plus Study started in September 2017 ${ }^{\mathrm{b}}$ Blood sample biomarkers determined in the blood sample, assessment of blood pressure and measurement of grip strength are described in detail in ESM.pdf. TICS-M: Telephone Interview Cognitive Status-Modified (see Table 2); IQ-COde Informant Questionnaire on Cognitive Decline in the elderly short form (see Table 2) 
Table 2 Neuropsychological tests and questionnaires

\begin{tabular}{|c|c|c|}
\hline Domain or goal & Assessment/questionnaires & $\begin{array}{l}\text { Duration } \\
\text { (min) }\end{array}$ \\
\hline \multicolumn{3}{|l|}{ Cognitive functioning } \\
\hline \multirow[t]{4}{*}{ Overall cognitive functioning } & Researcher subjective impression of cognitive health (see "Methods") & 0 \\
\hline & Mini-Mental State Examination $[26,86]$ & 5 \\
\hline & National Adult Reading Test ${ }^{\mathrm{a}}[88-89]$ & 3 \\
\hline & Telephone Interview Cognitive Status-Modified (TICS-M) ${ }^{\mathrm{d}}[90]$ & \\
\hline \multirow[t]{3}{*}{ Memory } & CERAD 10-word list—immediate and delayed recall [91] & 15 \\
\hline & Visual Association Test-Memory [92] & 5 \\
\hline & Rivermead Behavioral Memory Test $(\mathrm{RBMT})^{\mathrm{b}}$ immediate and delayed recall $[93,94]$ & 6 \\
\hline \multirow[t]{2}{*}{ Attention } & Digit Span—forwards [96-97] & 3 \\
\hline & Trail Making Test A $[98,99]$ & NA \\
\hline \multirow[t]{6}{*}{ Executive functions } & Digit Span—backwards [96-97] & 3 \\
\hline & Letter Fluency-DAT [101-104] & 2 \\
\hline & BADS—subtest Key Search $[105,106]$ & 3 \\
\hline & BADS—subtest Rule Shift Cards $[105,106]$ & 3 \\
\hline & Trail Making Test B $[98,99]$ & 10 \\
\hline & Amsterdam Dementia Screening Test—Meander figure [107] & 2 \\
\hline \multirow[t]{2}{*}{ Language } & Category Fluency-Animals $[100,101,108]$ & 2 \\
\hline & Visual Association Test—Naming [92] & 1 \\
\hline \multirow[t]{3}{*}{ Visuo-spatial functioning/construction } & CAMDEX-R/N CAMCOG-figure copying $[109,110]$ & 3 \\
\hline & Clock Drawing Test $[111,112]$ & 2 \\
\hline & $\begin{array}{l}\text { Visual Object and Space Perception (VOSP) Battery }{ }^{\mathrm{b}} \text { — subtest Number Location } \\
\text { [113] }\end{array}$ & 3 \\
\hline \multicolumn{3}{|c|}{ Depression, ADL, sleep, lifestyle, geriatric impairments } \\
\hline Depressive symptoms & Geriatric Depression Scale-15 (GDS) [29] & 4 \\
\hline \multirow[t]{2}{*}{ (Instrumental) Activities of daily living } & $\begin{array}{l}\text { Informant Questionnaire on Cognitive Decline in the elderly short form (IQ-CODE) } \\
{[30,31]}\end{array}$ & 3 \\
\hline & Barthel Index [27, 115-116] & 3 \\
\hline $\begin{array}{l}\text { Lifetime cognitively stimulating } \\
\text { experience }\end{array}$ & Lifetime Cognitive Activity Scale $^{\mathrm{a}}[34,35]$ & 5 \\
\hline Sleep quality & Pittsburgh Sleep Quality Index ${ }^{a}$ (PSQI) [28] & 5 \\
\hline Geriatric impairments & Researcher subjective impression of sight, hearing, mobility ("Methods") & 0 \\
\hline
\end{tabular}

${ }^{\mathrm{a} O n l y}$ administered at baseline, ${ }^{\mathrm{b}}$ In 100-plus Study-phase 1 only, ${ }^{\mathrm{c}}$ Included with the confirmation letter of study-inclusion, collected during the first baseline visit, ${ }^{\mathrm{d}}$ Only administered during half yearly-follow up of brain donors and yearly follow-up of siblings

\section{Lifetime/demographic characteristics}

To investigate the family genealogy and disease occurrence, we draw a pedigree including children, siblings, parents and grandparents, their (maiden) names, gender, birth years, age at death and cause of death, occurrence of dementia/cognitive decline (Fig. 3). To determine socioeconomic background (SEB) and socioeconomic status (SES) we inquire about the main occupation of the father and mother of the centenarian, the main occupation of the centenarian him/herself at adulthood and the main occupation of their partner(s). We inquire about the education level and the number of years education was followed. Education levels were classified according to (I) ISCED
1997 [32] and according to the classification system used in the Dutch 1971 census [33].

\section{Lifetime habits}

We address smoking habits and alcohol consumption (see ESM.pdf). We administer the Cognitive Activity Questionnaire (CAQ) [34, 35] to investigate cognitive stimulating experience during adult life (from childhood to 50 years) and current cognitively stimulating experience. 


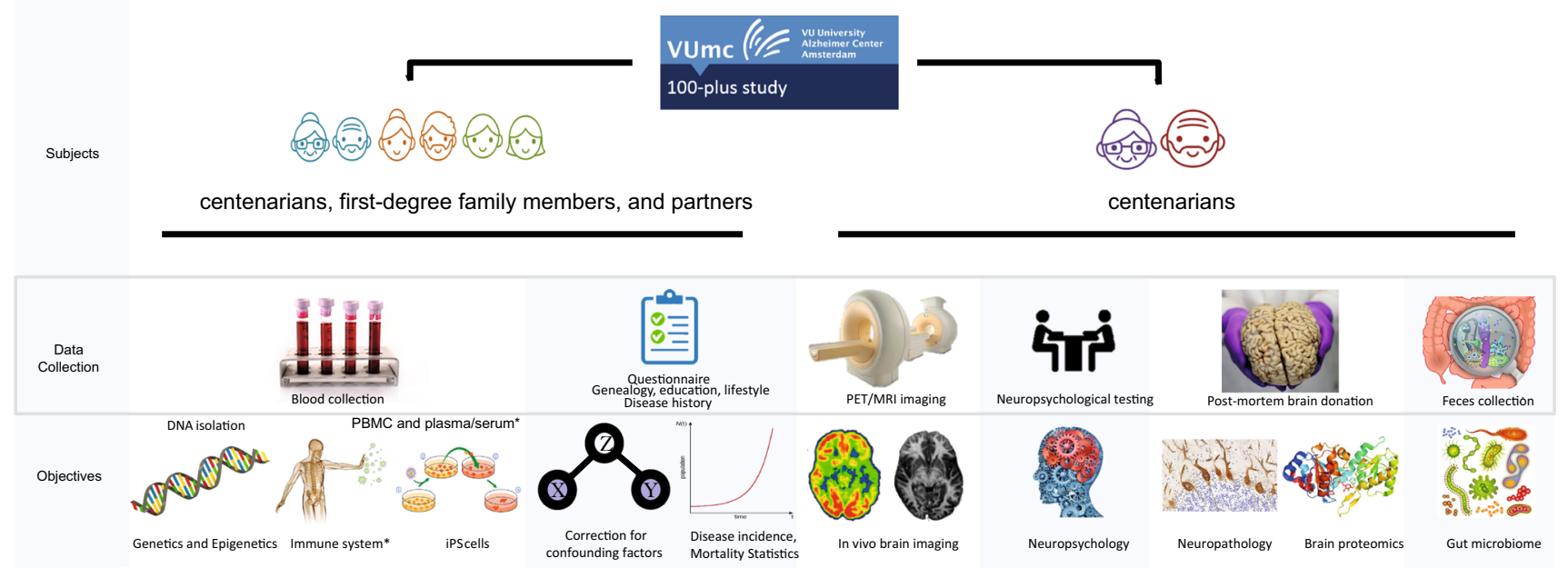

Fig. 1 Overview of the 100-plus Study, Phase 2: During home visits we inquire about life-history of the centenarians, their family history, medical history, and current health. We assess their performance on neuropsychological tests, measure blood pressure and grip strength and we collect a blood sample, for blood testing and genetic analyses. Optional parts of the study are: a visit to the outpatient clinic for PET-MRI and/or PET-CT imaging, feces donation to investigate the gut microbiome, and the generation of iPS cells from peripheral

\section{Data-collection of first degree living centenarian-relatives and partners}

For centenarian siblings and their partners, we administer the MMSE at the study inclusion visit and we record the genealogy at the level of the centenarian-generation (Fig. 3). We will yearly monitor changes in physical well-being and in cognitive health using TICS-M and IQCode-N. We ask centenarian-children and partners to fill in an abbreviated version of the centenarian questionnaire; we record the genealogy of the centenarian-generation, no cognitive testing will be administered; we will not followup centenarian-children and their partners (Table 1).

\section{Biomaterials}

\section{Biomaterial collection}

We collect a blood sample from centenarians and their family members for DNA isolation, peripheral blood mononuclear cells (PBMCs), plasma, serum, and when consent is given for generation of induced pluripotent stem cells (iPSCs) (Fig. 3). DNA samples are currently used for APOE genotyping, GWAS, whole exome sequencing (WES) and Sanger sequencing. Furthermore, all centenarians are informed about the option for feces donation for gut microbiome analysis, PET-MRI or PET-CT brain scans for in vivo detection of amyloid beta presence and structural brain imaging. We also inform about the option of post-mortem brain donation. Brain autopsies are blood. Furthermore, all participants are informed about the option of post-mortem brain donation in collaboration with the Netherlands Brain Bank [37]. This is optional and not required for study participation. We evaluate changes in general well-being and in neuropsychological test performance during (half-)yearly follow-up visits. Next to the centenarians, we also include their first-degree family members and their partners. *Collected in Phase- 2 of the 100-plus Study, started in September 2017

performed in collaboration with the Netherlands Brain Bank [36, 37]. For numbers of collected biomaterials thus far, please see additional data (ESM.pdf).

\section{Data storage}

OpenClinica open source software (version 3.1 onwards) is used for data management [38]. Biomaterials are stored in the biobank of the Amsterdam UMC.

\section{Cohort description}

\section{Included centenarians}

Between January 1st 2013 and September 1st 2018, 332 centenarians were included in the study of whom almost $30 \%(\mathrm{n}=92)$ agreed to post mortem brain donation. Thus far, 58 centenarians have come to autopsy. On June 21st 2017, 764 centenarians were approached for study-participation of which $300(40 \%)$ met study-inclusion criteria and were included in the study (Fig. 4). Here, we describe the cohort using the collected data from these first 300 centenarians. For all cohort descriptives see Table 5.

The mean age at inclusion of centenarians was $101.3 \pm 1.7$ years (ESM.pdf Fig S1A). The majority of centenarians were born between 1910 and 1917 (ESM.pdf Fig S1B). Of the 300 centenarians in the cohort, 284 were born in a Dutch municipality, 6 were born in the Dutch East Indies, (a Dutch colony at the time), and 10 


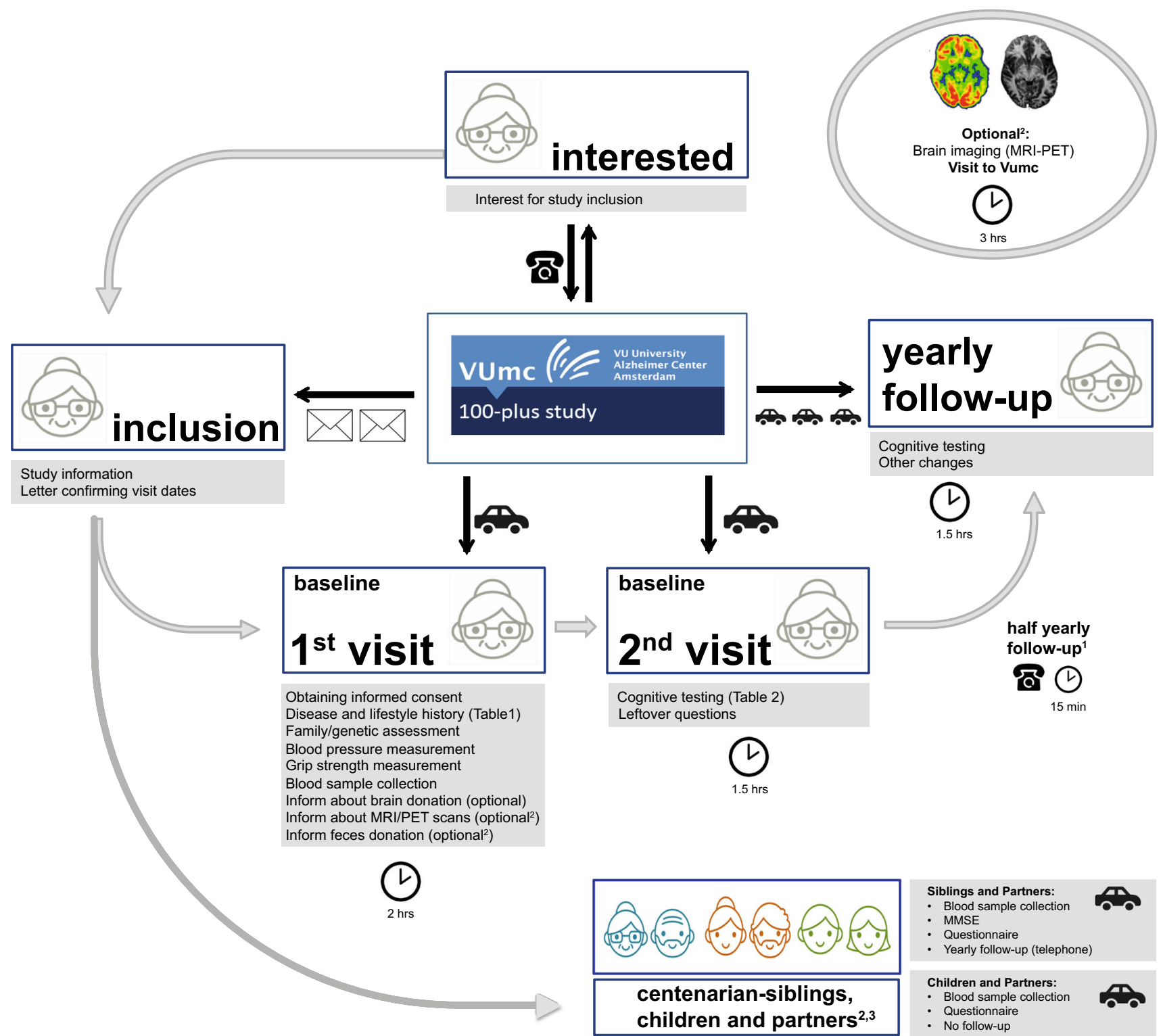

Fig. 2 Diagram of visit procedures of 100-plus Study: ${ }^{1}$ Half yearly follow-up by telephone is performed for centenarians who agreed to brain donation. ${ }^{2}$ Collected in phase- 2 of the 100 -plus Study, started in

centenarians were born in other European countries. Centenarian birth-municipalities indicated that the catchment area is spread across the 11 provinces of the Netherlands in the early 1900's (ESM.pdf Fig S2).

\section{Presentation at baseline}

Subjective researcher estimates of geriatric sensory impairments indicated that $87 \%$ of the centenarians had moderate-good hearing abilities (ESM.pdf Fig S3A), that $77 \%$ of the centenarians had moderate-good vision (ESM.pdf Fig S3B), and that $80 \%$ of the centenarians were independently mobile (ESM.pdf Fig S3C). The majority
September 2017. ${ }^{3}$ Data from centenarian-children and children inlaws will be obtained during the visit with the centenarian

(52\%) of the centenarians in the cohort lived independently (i.e. community dwelling without assistance, or independent in a residence with available services), $42 \%$ lived in private quarters in a residential care center, while only $1.7 \%$ of the centenarians lived in a nursing home (ESM.pdf Fig S3D). Centenarians scored a median of 15 points (IQR 12-18), on the Barthel index: $45 \%$ of the centenarians scored between 15 and 19, which indicates a need for minimum help with activities of daily living (ADL), while $32 \%$ scored 20 points which indicates they are fully independent in ADL (ESM.pdf Fig S3E). The centenarians in the cohort have no or very few symptoms of depression: they scored a median of 2 points on the 15 -items version of 
Table 3 Categorization of vision, hearing and mobility ability

\begin{tabular}{llll}
\hline & Vision & Hearing & Mobility \\
\hline Good & $\begin{array}{l}\text { Able to read newspapers and watch } \\
\text { television }\end{array}$ & $\begin{array}{c}\text { Able to have and follow a conversation in a group } \\
\text { of people }\end{array}$ & $\begin{array}{c}\text { Able to walk independently (with or } \\
\text { without help of a walking stick or } \\
\text { walker) }\end{array}$ \\
Moderate & $\begin{array}{l}\text { Able to read large texts with large } \\
\text { letters and watch television }\end{array}$ & $\begin{array}{c}\text { Able to have a conversation with one person/ } \\
\text { questions do not have to be repeated }\end{array}$ & $\begin{array}{c}\text { Able to walk with help of another } \\
\text { person }\end{array}$ \\
Poor & $\begin{array}{l}\text { Not able to watch television/vision } \\
\text { problems cause some difficulties in }\end{array}$ & $\begin{array}{c}\text { Limited ability to have a conversation with one } \\
\text { person/questions need to be repeated multiple } \\
\text { ADL }\end{array}$ & $\begin{array}{c}\text { Able to move independently in a } \\
\text { wheelchair }\end{array}$ \\
Very & Limited or complete loss of vision \\
poor & which causes severe difficulties in & $\begin{array}{c}\text { Not able to have a conversation with one person; } \\
\text { this does not improve when speaking loud and } \\
\text { clearly }\end{array}$ & $\begin{array}{c}\text { Not able to move independently in a } \\
\text { wheelchair }\end{array}$ \\
\hline
\end{tabular}

Vision and hearing abilities were estimated while participants used all available devices to support their vision and/or hearing

the Geriatric Depression Scale (IQR 1-3), and scores $<5$ indicate no evidence for depression [29] (ESM.pdf Fig S3F).

\section{Disease prevalence and multi-morbidities}

In June 2017 we had received GP reports from 209 centenarians, and categorized diagnosed conditions (Table 4). At baseline, centenarians were diagnosed with or had symptoms of on average $3.7 \pm 1.5$ morbidities (ESM.pdf Fig S3G). Cardiovascular problems are the most common condition in centenarians $(83.7 \%$ has at least one mention of a cardiovascular condition in their GP report). And hypertension is mentioned in the GP reports of almost half of all centenarians. Removal of hypertension from the list of cardiovascular conditions still leaves $66.5 \%$ of the centenarians with at least one mention of a cardiovascular condition (Table 4). Musculoskeletal disease and hypertension were more prevalent in females (72 vs. $39 \%$ and 54 vs. $34 \%$ ), while cardiovascular conditions were more prevalent in males (77 vs. 63\%). Most aging-associated diseases were first mentioned in the GP report when the centenarian was $>90$ years old, suggesting a seemingly high age at onset. As we cannot correct for methodological differences in data collection by GPs, we were not able to perform a systematic comparison with disease incidence statistics from prospective cohort studies (for further explanation see 'age at disease onset' analysis in ESM.pdf).

\section{Cognitive function (Mini Mental State Examination, MMSE)}

At cohort inclusion, the average raw MMSE score was $23.9 \pm 4.4$ points. We adjusted for missing items due to hearing or vision impairments, which allowed us to directly compare MMSE scores between centenarians (see Methods). At study inclusion the average adjusted MMSE score of the 100-plus Study cohort was $24.3 \pm 4.23$ points (median score 25, IQR 22.0-27.5) (Fig. 5a). For 287 centenarians, a trained researcher estimated cognitive health. The large majority (83\%) of the centenarians was subjectively estimated to be cognitively healthy, and this group scored a median of 26 points on the MMSE (IQR 23.5-28). This was significantly higher than the median MMSE score of 19 (IQR 16.4-22) by the 41 centenarians for whom cognitive health was "doubted" ( $p=4 \times 10^{-3}$, two-tailed $t$ test with unequal variance), and the median MMSE score of 8 centenarians who were estimated to have "probable cognitive impairment" was 16.4, (IQR 12.8-17) (Fig. 5b).

\section{MMSE and mortality rates}

The mortality percentage (presented per annual-year) underestimates the mortality at extreme ages, such that we prefer presenting the instant mortality rates (presented per life-year); for rationale and calculation procedures see ESM.pdf. Within the group of 293 participants for which a baseline MMSE was available, there were 67 deaths that occurred before a next planned visit: the planning of a next visit was used to confirm which centenarians were still alive and who had died. There were 41 confirmed deaths that occurred before a planned first-year follow-up visit, and 174 centenarians were confirmed alive at the time of their first-year follow-up visit. The overall mortality rate in the first year after inclusion was 0.24 deaths per life-year (95\% CI 0.17-0.32); which relates to a mortality percentage of $21 \%$ per annual year (95\% CI 16-27\%). Specifically, the 106 centenarians who scored $\geq 26$ on the MMSE at baseline had a mortality rate of 0.19 deaths per life-year (95\% CI 0.11-0.29), while the 109 centenarians with baseline MMSE scores $<26$ had a mortality rate of 0.29 deaths per life-year (95\% CI 0.19-0.43) ( $p=0.075)$. Of the 91 centenarians who were eligible for a second follow-up visit, there were 20 confirmed deaths before this visit, and 71 were confirmed alive at the time of this visit. Therefore, 
Table 4 Categories of conditions analyzed in the GP medical files of 209 centenarians

Condition-category Conditions

Fraction of centenarians with at least one mention of Fraction of centenarians with a at least one mention of these conditions in their GP this condition in their GP report $(\%)$

Cardiovascular disease $(83.7 \%)$

Cardiovascular disease without hypertension $(66.5 \%)$

Musculoskeletal (63.2\%)

Vision $(41.6 \%)$

Hearing $(30.6 \%)$

Cancer $(27.8 \%)$

Autoimmunology (22\%)

Urology (21.5\%)

Neurology/psychiatry $(15.8 \%)$

Gastrointestinal (15.3\%)

Lung disease $(10.5 \%)$

Other report $(\%)$

Hypertension (48.8\%); congestive heart failure (29.7\%); cardiac dysrhythmia (23\%); CVA/TIA (18.7\%); angina pectoris (15.3\%); myocardial infarction $(8.1 \%)$; valvular heart disease $(8.1 \%)$; thrombosis $(6.2 \%)$; pacemaker $(5.7 \%)$; aortic stenosis $(2.9 \%)$; amputation leg (1.4\%); coronary bypass $(1 \%)$; hypercholesterolemia (1\%); arterial disease $(0.5 \%)$; arteritis temporalis $(0.5 \%)$; atherosclerosis $(0.5 \%)$; cerebrovascular insufficiency $(0.5 \%)$; coronary sclerosis $(0.5 \%)$; intermittent claudication $(0.5 \%)$; orthostatic hypotension $(0.5 \%)$; pericarditis $(0.5 \%)$

Arthrosis (35.4\%); fractures (34.4\%); osteoporosis (14.8\%); joint(s) replacement (11.5\%); osteoarthritis $(3.3 \%)$; hernia $(1 \%)$

Cataract (30.1\%); macular (7.7\%); glaucoma (3.8\%); vision impairment (2.4\%)

Hearing impairment $(30.6 \%)$; cholesteatoma $(0.5 \%)$; sudden deafness $(0.5 \%)$

Skin cancer (17.2\%); breast cancer $(4.3 \%)$; colon cancer (4.3\%); prostate cancer $(1.9 \%)$; uterus cancer $(1.4 \%)$; bladder cancer $(0.5 \%)$; choleasteatome $(0.5 \%)$; palate cancer $(0.5 \%)$; stomach cancer $(0.5 \%)$; thyroid cancer $(0.5 \%)$; vocal chord cancer $(0.5 \%)$

Diabetes (7.7\%); rheumatoid arthritis (4.8\%); hyperthyroidism (3.8\%); hypothyroidism (3.3\%); skin cancer $(1.4 \%)$; asthma $(1 \%)$; hypopituitarism $(0.5 \%)$; thyroid enlargement $(0.5 \%)$; thyroid removal $(0.5 \%)$

UTI (7.2\%); incontinence (5.7\%); prostate hypertrophy (4.8\%); hysterectomy (1.9\%); uterine prolapse $(1.9 \%)$; catheter $(1 \%)$; prostate resection hypertrophy $(1 \%)$; ovarian cysts $(0.5 \%)$;

Balance (3.3\%); cognitive decline (2.9\%); depression (2.4\%); psychiatry $(2.4 \%)$; epilepsy (1.9\%); delirium (1.4\%); insomnia (1\%); Parkinson's (1\%); dizziness $(0.5 \%)$; migraine $(0.5 \%)$; tremor $(0.5 \%)$; WM atrophy $(0.5 \%)$

Kidney failure $(6.7 \%)$; gastric ulcer $(1.9 \%)$; cholecystectomy $(1.4 \%)$; diverticulosis $(1.4 \%)$; gall stones $(1.4 \%)$; kidney stones $(1 \%)$; reflux esophagitis $(1 \%)$; appendectomy $(0.5 \%)$; intestinal polyps $(0.5 \%)$; pancreatitis $(0.5 \%)$; rectal prolapse $(0.5 \%)$; sigmoid resection $(0.5 \%)$

Pneumonia (6.2\%); COPD (2.4\%); TBC (1.9\%); Emphysema $(0.5 \%)$; ulcer $(0.5 \%)$

Erysipelas (1.4\%); anemia (1\%); herpes zoster $(1 \%)$; other $(1 \%)$; restless legs $(1 \%)$; eye infection $(0.5 \%)$; itching $(0.5 \%)$; pes equinus $(0.5 \%)$; vitamin B deficiency $(0.5 \%)$; vitiligo $(0.5 \%)$

Left column: when multiple conditions that belong to one condition-category are mentioned more than once in the GP report of a centenarian, they are counted as one. Right column: all conditions are counted separately, even though they belong to one condition-category. In aggregate, the percentages in the right column will exceed the percentage in the left column

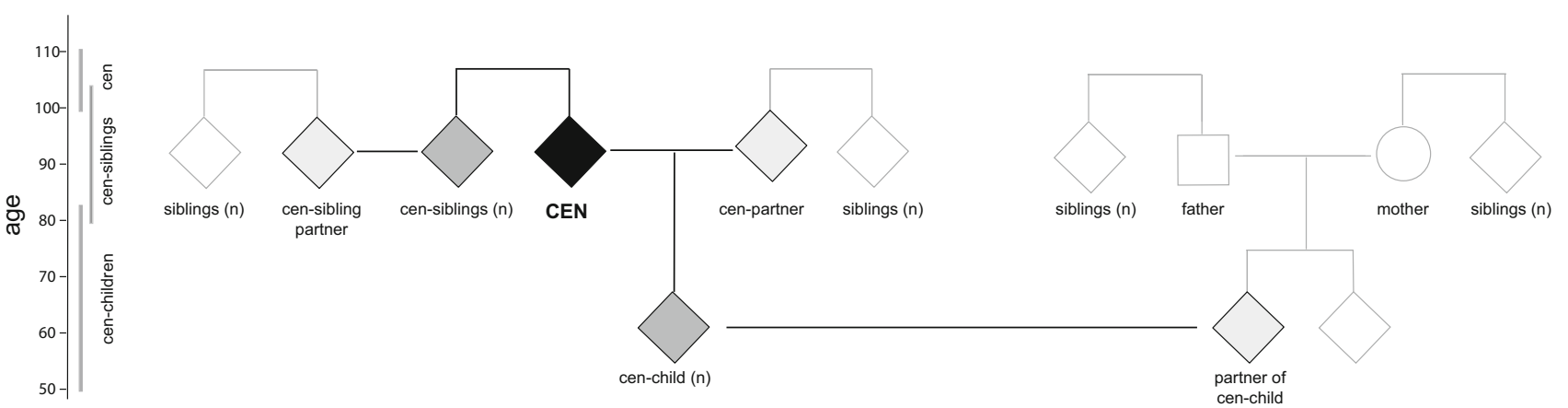

Fig. 3 Data collection from centenarians and their family-members: In Phase-2 of the 100-plus Study (since September 2017), we obtain blood-samples from centenarians (black), and when willing, their siblings, their children (dark grey) and their respective partners (light grey). We will inquire about longevity and incidence of dementia in relatives from the same generation as the centenarian (white). Square: male, circle: female, diamond: both genders are possible 


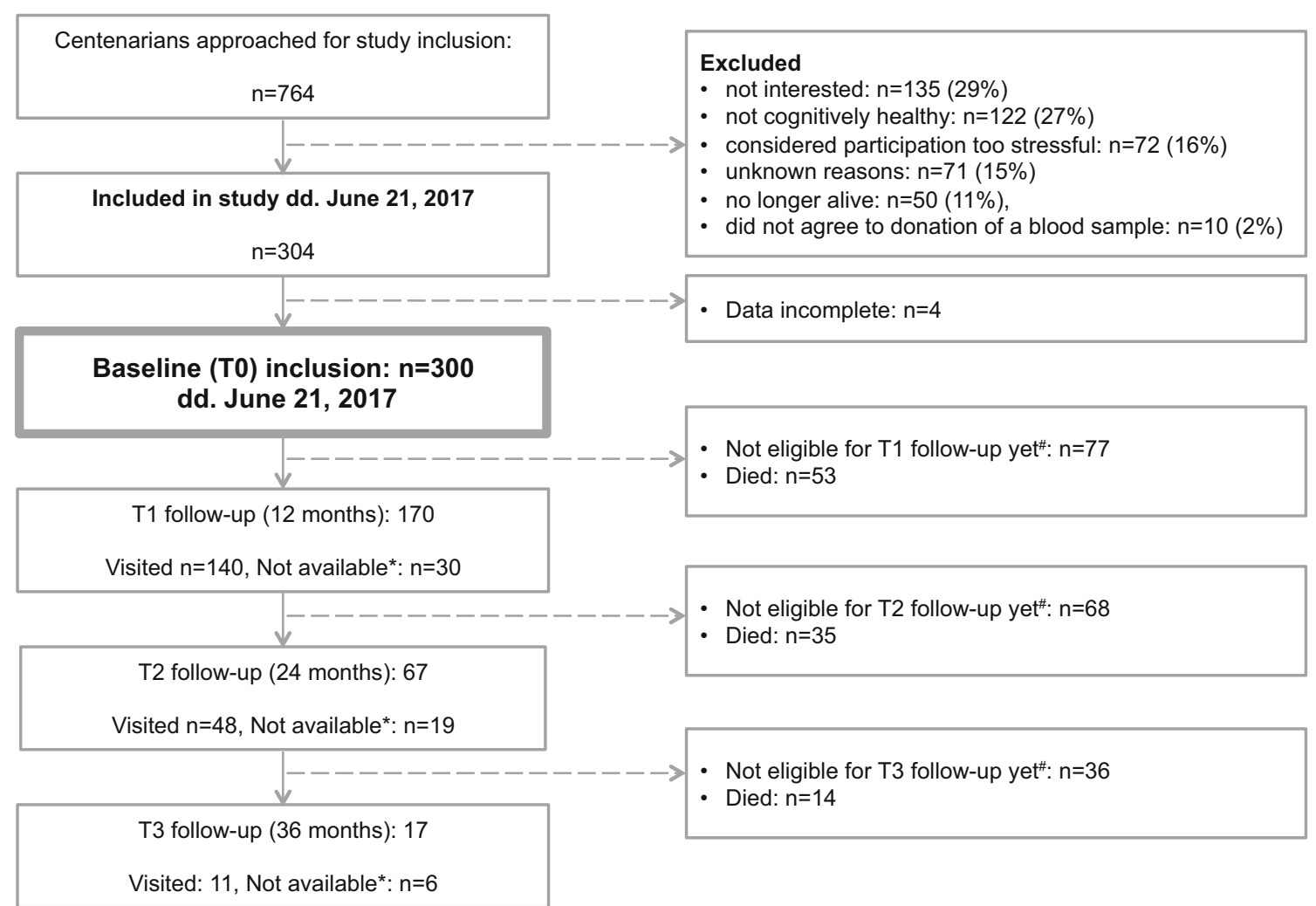

Fig. 4 Flowchart of study inclusion: *Not available: centenarians were on vacation, not interested or too frail for a follow-up visit. When possible, follow-up was performed by telephone and/or informant questionnaires. In several cases, centenarians were

in the second year after baseline, the mortality rate increased to 0.32 deaths per life-year (95\% CI 0.20-0.49); which relates to a mortality percentage of $28 \%$ per annualyear (95\% CI 18-39\%). Specifically, the mortality rate of the centenarians who scored $\geq 26$ points at baseline remained at a low 0.19 deaths per life-year (95\% CI $0.08-0.37$ ), while the mortality rate of centenarians who scored $<26$ points increased to 0.54 deaths per life-year $\left(95 \%\right.$ CI 0.29-0.90) $\left(p=3.0 \times 10^{-3}\right)$ (Fig. 5c). Mortality rates and related mortality percentages are presented in Table 4.

\section{Education}

We compared centenarian-education levels with individuals from the same birth cohort (1912-1916): 55-59 yearolds as reported in the Dutch population in the 1971 census [39]. Both centenarian-males and females attained significantly higher levels of education compared to their birth cohort in the 1971 census [33] $\left(p<1 \times 10^{-5}\right.$, MannWhitney U test) (ESM.pdf Fig S4A). Specifically, 79\% of the centenarian males and $66 \%$ of the centenarian females attained more than basic education, compared to respectively $45 \%$ and $31 \%$ of the males and females in their birth available for follow-up one year later, such that this 'unavailable' group was formally kept in the study until death. "Not eligible: centenarians were not yet included in the study long enough to be eligible for the next follow-up visit

cohort (Table 5). Workers and self-employed persons with little education were overrepresented in the $\sim 20 \%$ nonresponders in the 1971 census, suggesting that this is a conservative estimate of the differences [33].

\section{Socio-economic background and status}

Based on paternal professions, centenarian-socio-economic background (SEB) was compared to 2815 individuals born between 1910 and 1915 from the Historical Sample of the Netherlands (HSN) [40] $\left(p<1 \times 10^{-5}\right.$, Mann-Whitney U test) (ESM.pdf Fig S4B-left). Centenarian-fathers were threefold more likely to have an eliteupper middle class occupation and $>3$-fold less likely to be an unskilled worker compared to their birth cohort. Based on the professions of the 219 centenarian-males and centenarian-female-partners, centenarians themselves attained a significantly higher SES than the 408 males from the HSN sample born between 1910 and 1919 ( $p<1 \times 10^{-5}$, Mann-Whitney $\mathrm{U}$ test). Centenarians were $>4$-fold more likely to be elite-upper middle class, $>2$-fold more likely to be farmers, and $>3$-fold less likely to be unskilled or farm workers (ESM.pdf Fig S4Bright). There was no difference between the socio- 
Table 5 Descriptive statistics of 100-plus Study cohort

\begin{tabular}{|c|c|c|}
\hline \multicolumn{3}{|l|}{ Cohort statistics } \\
\hline 100-plus cohort, June 2017 ( $\mathrm{N}$ available，\%) & 300 & \\
\hline Age at inclusion (mean, SD) & $101.3 \pm 1.7$ & \\
\hline Birth years (median, IQR) & $1914(1913-1915)$ & \\
\hline Brain donors $(\mathrm{n}, \%)$ & $81(27 \%)$ & \\
\hline \multicolumn{3}{|l|}{ Follow-up visits } \\
\hline T0 baseline visits & 300 & \\
\hline T1 possible visits (visited, died, missed) & $223(140,53,30)$ & \\
\hline T2 possible visits (visited, died, missed) & $155(48,88,19)$ & \\
\hline T3 possible visits (visited, died, missed) & $119(11,102,6)$ & \\
\hline \multicolumn{3}{|l|}{ Mortality } \\
\hline Whole cohort & T0-T1 & $\mathrm{T} 1-\mathrm{T} 2$ \\
\hline Mortality rate $(95 \% \mathrm{CI})$ & $0.24(0.17-0.32)$ & $0.32(0.20-0.49)$ \\
\hline Mortality percentage (95\% CI) & $21 \%(16-27 \%)$ & $28 \%(18-39 \%)$ \\
\hline \multicolumn{3}{|l|}{ MMSE $<26$ at baseline $(95 \%$ CI) } \\
\hline Mortality rate $(95 \% \mathrm{CI})$ & $0.29(0.19-0.43)$ & $0.54(0.29-0.90)$ \\
\hline Mortality percentage (95\% CI) & $25 \%(17-35 \%)$ & $42 \%(25-59 \%)$ \\
\hline \multicolumn{3}{|l|}{ MMSE $\geq 26$ at baseline $(95 \%$ CI $)$} \\
\hline Mortality rate $(95 \% \mathrm{CI})$ & $0.19(0.11-0.29)$ & $0.19(0.08-0.37)$ \\
\hline Mortality percentage (95\% CI) & $17 \%(10-25 \%)$ & $17 \%(8-31 \%)$ \\
\hline
\end{tabular}

Cognitive functioning at baseline

Mini Mental State Examination (MMSE)

100-plus cohort (median MMSE, IQR)

$25(22.0-27.5)$

MMSE $>22^{\mathrm{a}}$ (fraction of cohort, \%)

$72.4 \%$

MMSE $\geq 26$ (fraction of cohort, \%)

$47.2 \%$

Estimated by trained researcher $(n=287)$

Cognitively healthy (fraction of cohort, \%; median MMSE (IQR)

$83 \%$; 26 (23.5-28.0)

Doubt

$14 \% ; 19(16.4-22.0)$

Cognitively impaired

$2.8 \% ; 16.4(12.8-17)$

Baseline presentation

\section{Geriatric impairments}

Mobile: without aids

$80.2 \%$

Hearing: moderate-Good

$86.8 \%$

Vision: moderate-Good

$77.1 \%$

Maintained continence

$56.3 \%$

Number of comorbidities (avg $\pm \mathrm{SD}$ )

$3.7 \pm 1.5$

Geriatric depression scale: $\leq 5$ (no depression)

$91.5 \%$

Living independence

Community dwelling/private residence with care available

Private quarters in residential care center

$42.0 \%$

Independence in Activities of Daily Living (Barthel Index)

Needs minimal assistance (15-19)

Fully independent (20) 
Table 5 continued

Lifestyle characteristics

Smoking: regularly/often

Males $\quad 67 \%$

$\begin{array}{ll}\text { Females } & 15 \%\end{array}$

Alcohol consumption: regularly/often

Males $\quad 54 \%$

$\begin{array}{ll}\text { Females } & 31 \%\end{array}$

Demographic characteristics

Education $>$ basic (primary school)

Centenarians versus population ${ }^{\mathrm{b}, \mathrm{c}}$

Males

79 versus $45 \%$

Females

66 versus $31 \%$

Socioeconomic status

SEB: Social class father: $\geq$ lower-middle class

31.2 versus $17.9 \%$

SES: Social class-centenarian or -partner: $\geq$ lower-middle class

55.5 versus $29.4 \%$

Number of children parented: (mean \pm SD)

$3.9 \pm 2.2$ versus $3.5 \pm 2.5$

\begin{tabular}{lll}
\hline APOE genotypes & & \\
\hline APOE genotypes & Genotype frequency $(\%) ;$ centenarians versus population ${ }^{\mathrm{d}}$ & Odds ratio $(95 \% \mathrm{CI}) ; p$ value $^{\mathrm{e}}$ \\
$\varepsilon 2 / \varepsilon 2$ & 0.9 versus $0.7 \%$ & $1.30(0.3-5.7) ; p=9.6 \times 10^{-1}$ \\
$\varepsilon 2 / \varepsilon 3$ & 24.9 versus $11.7 \%$ & $2.49(1.8-3.5) ; p=3.4 \times 10^{-7}$ \\
$\varepsilon 2 / \varepsilon 4$ & 4.8 versus $3.0 \%$ & $1.63(0.8-3.1) ; p=2.1 \times 10^{-1}$ \\
$\varepsilon 3 / \varepsilon 3$ & 60.3 versus $60.5 \%$ & $0.99(0.8-3.1) ; p=8.9 \times 10^{-1}$ \\
$\varepsilon 3 / \varepsilon 4$ & 8.7 versus $21.3 \%$ & $0.35(0.2-0.6) ; p=5.7 \times 10^{-7}$ \\
$\varepsilon 4 / \varepsilon 4$ & 0.4 versus $2.9 \%$ & $0.15(0.0-1.1) ; p=3.2 \times 10^{-3}$ \\
APOE alleles & & $2.1(1.6-2.8) ; p=4.8 \times 10^{-7}$ \\
$\varepsilon 2$ & 17 versus $10.7 \%$ & $1.0(0.8-1.3) ; p=1.0$ \\
$\varepsilon 3$ & 86.1 versus $87.1 \%$ & $0.44(0.31-0.63) ; p=6.3 \times 10^{-7}$
\end{tabular}

${ }^{\mathrm{a}}$ An MMSE $>22$ is the suggested cutoff score for cognitive health in elderly aged 97 years and above [117], ${ }^{\mathrm{b}}$ Centenarian education levels were compared with 54-61 years olds reported in the Dutch population in the 1971 census [39], ${ }^{\mathrm{c}}$ Socio-economic background was compared with 2815 individuals born between 1910 and 1915 from the Historical Sample of the Netherlands (HSN) [40], ${ }^{\text {d }}$ APOE genotypes were compared with $2233 \sim 50-80$-year olds from the Longitudinal Aging Study Amsterdam (LASA) [45], ${ }^{\mathrm{e}} p$ values were calculated using a two-sided Fisher's Exact test

economic status (SES) attained as adults of 81 male centenarians and the male-partners of 138 female-centenarians ( $p=0.22$, Mann-Whitney U test).

\section{Smoking behavior and alcohol consumption}

Retrospective comparison of smoking behavior suggests that centenarians smoked less than a representative sample of Dutch individuals born between 1909 and 1923, as indicated in a 1958 survey $[41,42]$. Of the centenarian-males, $67 \%$ indicated to have smoked regularly or often during an extended period in their lives, while in 1958, 91\% of the birth cohort males reported to smoke. Of the centenarian females, $15 \%$ indicated to have smoked regularly or often while $32 \%$ of the birth cohort females smoked. Alcohol consumption was common among centenarians: only $11 \%$ of the centenarian-males and $22 \%$ of the centenarian-females indicated to never consume alcohol, similar to $14 \%$ of male-abstainers and $21.8 \%$ female-abstainers among the birth cohorts in the 1958 survey [41]. In fact, 54\% of the centenarian-males and $31 \%$ of the centenarian-females indicated to consume alcohol regularly or often.

\section{Marriage and children}

Centenarians had on average $3.9 \pm 2.2$ children, which was more than the average $3.5 \pm 2.5$ children from 860 Dutch parents born between 1910 and 1915 [43] ( $p=0.03$, Mann-Whitney U) (ESM.pdf Fig S4C). However, we cannot exclude that lifestyle differences (i.e. religious or regional customs) might confound this increased fertility. Overall, $91 \%$ of the centenarians was ever-married, and 

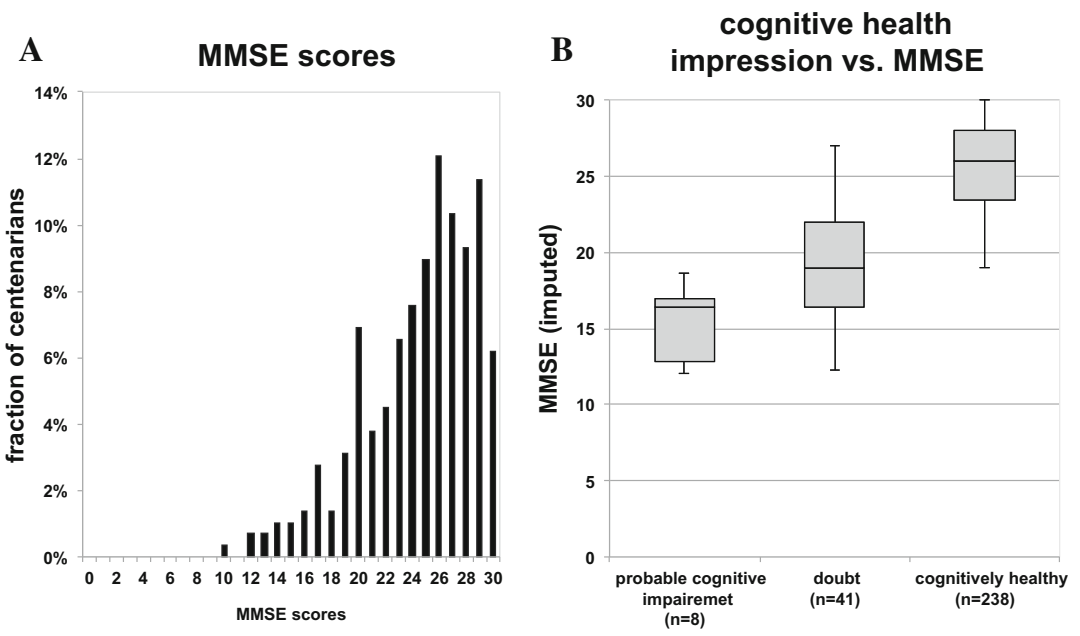

C
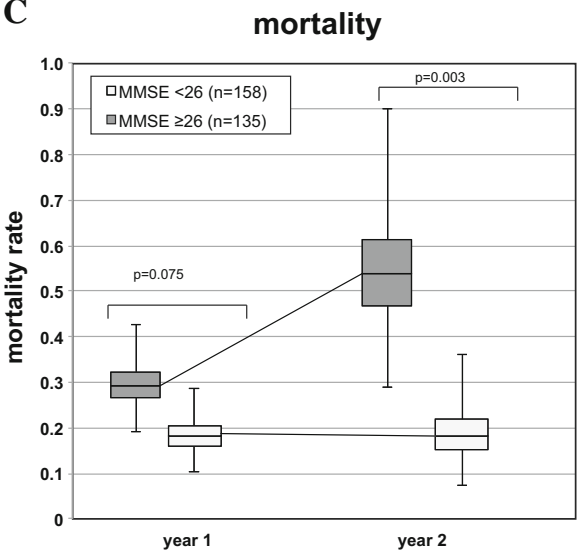

Fig. 5 Overall cognitive functioning (Mini-Mental State Examination): a Mini-Mental State Examination (MMSE) scores. b Researcher impression of cognitive health at first visit, compared to

$86 \%$ had one or more children. Of the centenarian females, $16.5 \%$ remained childless (36/219), similar to the $16 \%$ childless females born between 1915 and 1919 [44]. Five males in the cohort $(6 \%)$ remained childless (birth cohort data not available [44]).

\section{APOE allele frequency}

APOE was genotyped for 266 centenarians (ESM.pdf Fig S5). Centenarians were $>2$-fold more likely to carry an $A P O E$ - $\varepsilon 2$ allele than 2233 Dutch population controls aged 60-80 years [45]. Specifically, centenarians are 2.5-fold more likely to have the $A P O E-\varepsilon 2 / \varepsilon 3$ genotype (Table 5). In contrast, centenarians are $>2$-fold less likely to carry an $A P O E-\varepsilon 4$ allele compared to the Dutch population; specifically, centenarians are 2.8-fold less likely to be genotyped $A P O E-\varepsilon 3 / \varepsilon 4$ and 6.7-fold less likely to have the $A P O E-\varepsilon 4 / \varepsilon 4$ genotype. The allele frequency of the $A P O E \& 3$ allele was identical for both cohorts.

\section{Discussion}

Here, we present the 100-plus Study cohort of cognitively healthy centenarians based on the first 300 centenarians included in the 100-plus Study.

\section{On average, the centenarians in the 100-plus Study cohort have a high performance on the MMSE; the large majority is independent and retained hearing and vision abilities}

Our inclusion criteria of "self-reported cognitive health, which is confirmed by an informant" led to a selection of centenarians with a relatively high level of overall
MMSE score. c Mortality rate of centenarians with high and low performance on the MMSE

cognitive functioning. The cohort scored an average $23.9 \pm 4.4$ points on the MMSE (raw, unimputed), which is considerably higher than the average MMSE score of $\sim 17$ points, by representative centenarian populations (16.2 \pm 8.8 points, Georgia Centenarian Study [46]; $18.7 \pm 7.4$, Italian centenarians from Rome and surroundings [47]; $17.7 \pm 8.3$ centenarians from Northern Italy [48]). The overall cognitive performance of the 100-plus cohort participants is similar to "community-dwelling cognitively healthy centenarians" from the Georgia centenarian Study [49], and "cognitively healthy" Japanese centenarians, who respectively scored a mean of 24.8 points and $22.3 \pm 3.32$ points on the MMSE [50].

Next to their retained cognitive functioning, the large majority of the centenarians had moderate-good hearing and vision abilities, they were independently mobile, they enjoyed a relatively high level of independence in activities of daily living (ADL), and had no or few symptoms of depression. Centenarians were either community dwelling or lived independently in a residence or in a care center with available services. Together, these findings underscore that the 100-plus Study cohort is not a representative population of Dutch centenarians, rather, it represents a high-performing, independent sub-selection of Dutch centenarians.

\section{Cognitive performance is associated with mortality}

The mortality in our cohort was $21 \%$ per annual year, which is two-fold lower relative to the centenarians in the general Dutch population [51]. In the second year after baseline centenarians with high cognitive functioning at baseline retained a low mortality rate of $17 \%$ per annualyear, while centenarians with lower cognitive function at 
baseline had a mortality rate of $42 \%$ per annual-year. These findings confirm that we have succeeded in selecting the healthiest of the centenarians, as we assume that these will be maximally enriched with protective (genetic) factors. Our results further confirm that there is an overlapping etiology of maintained cognitive and overall health, and cognitive functioning $[52,53]$. The longitudinal set-up of our study allows us to monitor changes in cognition in combination with other factors of overall health that occur between baseline and death to identify to which extent centenarians escaped or delayed cognitive impairment.

\section{The 100-plus cohort is twofold enriched with males}

The fraction of centenarian-males is $27 \%$, twice the fraction of males $(14.4 \%)$ in the total Dutch centenarian population on January 1st 2017 [54]. Indeed, since dementiaprevalence in centenarian populations is consistently lower in males $(\sim 40 \%)$ than in females $(\sim 60 \%)[55,56]$, we had on forehand expected that our inclusion criteria of "self-reported cognitive health, which is confirmed by an informant" might lead to a relative enrichment of centenarian males in the cohort. Based on the fraction of centenarian males in the population (14.3\% in 2017) and lower dementia prevalence in males ( 40 vs. $60 \%$ ), we estimated that the fraction of males in the 100-plus Study cohort should be approximately $20 \%$. This suggests that dementia incidence does not fully explain the excess of males in our cohort, which leaves room for, for example, the influence of a participation bias and a better general well-being of centenarian males [57].

\section{Disease in male and female centenarians}

Despite the cognitive health of the centenarians in the 100-plus Study cohort, they were diagnosed with on average four morbidities at baseline. Previous studies have shown that females are more prone to develop chronic nonfatal conditions such as dementia, arthritis and osteoporosis [58], while males are more likely to develop fatal conditions, such as cardiovascular disease and cancer [59, 60]. In agreement with these studies, we found that the females in the 100-plus Study cohort had a higher prevalence of musculoskeletal diseases and hypertension while males had a higher prevalence of heart disease and CVA/TIAs.

\section{The 100-plus Study cohort is equally depleted with the APOE- $\varepsilon 4$ allele compared to other centenarian cohorts, but it is strongly enriched with the neuroprotective APOE- $\varepsilon 2$ allele}

The 100-plus Study cohort was 2.3-fold less likely to carry the $A P O E-\varepsilon 4$ AD-risk allele compared to their birth cohort at $60-80$-years $\left(\mathrm{OR}=0.44, p=6.3 \times 10^{-7}\right)$ [45]. This is in complete concordance with the depletion of the $\varepsilon 4$ allele observed in a meta-analysis of 2776 (mostly Caucasian) centenarians and 12,000 controls $(\mathrm{OR}=0.43$, $p<1 \times 10^{-3}$ ) [61]. It is well established that carrying one or two $A P O E-\varepsilon 4$ alleles is associated with respectively a 3-5 and 10-30-fold increased risk of developing AD. Depletion of the APOE- $\varepsilon 4$ allele in centenarians confirms that $\varepsilon 4$ allele carriers dropped out of the population during aging [62]. On the other hand, carrying one protective $A P O E-\varepsilon 2$ allele is associated with a two-fold decreased lifetime risk of developing $\mathrm{AD}[63,64]$. But the large centenarian meta-analysis indicated that the protective aspect of the $A P O E-\varepsilon 2$ allele does not extend to an enrichment in centenarians $(\mathrm{OR}=1.08, \quad p=0.66)$, although weak evidence for an enrichment of the APOE$\varepsilon 2 / \varepsilon 3$ genotype was observed $\left(\mathrm{OR}=1.4, p=1.7 \times 10^{-2}\right)$ [61]. In contrast, we find strong evidence for an enrichment of the $A P O E-\varepsilon 2$ allele in cognitively healthy centenarians from the 100-plus Study cohort compared to their birth cohort at 60-80-years: centenarians were 2.1-fold more likely to carry the $A P O E-\varepsilon 2$ allele $\left(p=4.8 \times 10^{-7}\right)$, and 2.5 -fold more likely to have an $A P O E-\varepsilon 2 / \varepsilon 3$ genotype $\left(p=3.4 \times 10^{-7}\right)$. This confirms previous suggestive findings in a cohort of Italian centenarians who were free of dementia or any other major age-related conditions, which had a similar enrichment of the APOE- 22 allele [65]. We speculate that this enrichment of the $A P O E-\varepsilon 2$ allele is not a consequence of our selection of extreme ages, but that it reflects our selection of individuals with retained (cognitive) health until extreme ages.

The specific enrichment of the $A P O E-\varepsilon 2$ in the centenarians with high cognitive performance suggests that the etiology for reaching 100 years with maintained (cognitive) health may be distinct from the etiology of reaching 100 years in general. Our results indicate that while searching for (genetic) factors that maintain cognitive health, the $A P O E$ genotype should be taken into account.

\section{Centenarians came, on average, from higher socio-economic classes and had higher levels of education}

On average, centenarians came from a higher socio-economic background than their birth cohort. A high fraction of 
centenarian-fathers were farmers, mostly on their own farm, a common occupation in the Netherlands during the early twentieth century. As adults, centenarians attained a higher socio-economic status and they had more children compared to their birth cohort. Both male- and female-centenarians attained higher levels of education than the males and females from their birth cohorts. These findings reflect the selective survival advantage of individuals from the higher/ middle socioeconomic classes and farmers, during the majority of the twentieth century in the Netherlands [66]. Together, this is in agreement with results from several centenarian studies, which showed that socioeconomic background, educational attainment, and adult socioeconomic status influenced the chance to become a centenarian [67]. Likewise, having children associates with an increased chance of reaching extreme ages, likely due to the involvement of children in the care for their aged parent [68].

\section{Alcohol consumption of centenarians was similar to birth cohort peers, and they smoked-but less}

Two-thirds of the centenarian males and $15 \%$ of the centenarian females indicated to have smoked regularly or often during an extended period in their life. This was less than their birth cohort peers, of whom almost all males and a third of the females smoked [41]. Alcohol consumption of the centenarians was similar to their birth cohorts. These results are partly in agreement with lifestyle behaviours from the American Ashkenazi Jewish centenarians, whose alcohol consumption and smoking behaviour was not different from the general population [69].

We note that comparisons of lifestyle habits such as alcohol consumption and smoking rely on recall of habits from several decades ago, which may introduce recall bias. For this reason, we focused on investigating lifestyle factors that are manifest for a longer period during a lifetime. Habits that may be more variable throughout life, such as dietary or exercise habits, might be more difficult to recall and we chose to refrain from investigating these. Despite these limitations, a withincohort analysis of these variables may add to the rich phenotypic data available for this cohort.

\section{Conclusions}

The 100-plus Study cohort represents cognitively healthy Dutch centenarians. Compared to their birth cohort peers, centenarians from this cohort attained significantly higher levels of education, were from a higher socioeconomic background, attained higher socioeconomic status, and they had more children, all of which confirms previous findings that these factors are associated with the chance of reaching 100 years in cognitive health. The combined contributions of these features, which are often concentrated within families, and the enrichment with the genetically heritable $A P O E-\varepsilon 2$ allele, will most likely explain a considerable proportion of the high heritability of reaching 100 years with maintained cognitive health. However, these features do not apply to all centenarians, and only a third of the cohort carries the $A P O E-\varepsilon 2$ allele. This suggests that additional protective factors may account for the cohort phenotype.

With the recent developments in biotechnology, novel findings regarding the physiology of exceptional longevity and cognitive function are emerging [70, 71]. The availability of blood and brain tissues from the healthiest centenarians provides the opportunity to acquire insights in the molecular constellations associated with the long-term maintenance of cognitive health. Ultimately, with this cohort we aim to contribute to the generation of novel hypotheses regarding the generation of novel therapeutic targets that offer resilience to cognitive decline.

Acknowledgements We are grateful for the collaborative efforts of all participating centenarians and their family members and/or relations. We also want to acknowledge the many people who contributed and continue to contribute to the study. The students involved in recruiting and visiting the centenarians: Lieke Jansma, Lieve Steins Bisschop, Sanne Koole, Sanne Hofman, Anna Kamsteeg, Saiedah Wekker, Matteo Neumann, and Marlous Jansen. The personnel who facilitated data collection and storage in available biobanks: Michiel Kooreman, Annemieke Rozemuller, Jeroen Hoozemans, Hans Gille, Charlotte Teunissen. The persons who advised on the collection procedures of specific data: Quinten Waisfisz, Eus van Someren, Ted Koene, Bart van Berckel, Wiesje van der Flier, Vivi Heine, Erik Sistermans, Cornelia van Duijn. We thank Marcel Reinders and Sven van der Lee for critically reviewing the manuscript before submission.

Authors' contributions HH conceived and designed the study and wrote the manuscript; NB helped obtain ethical approval for the study and with the management of communication with participants and their proxies; TD is dedicated GP and analyzed GP reports, KP, EW, KS, LT, DB and SR visited the centenarians and helped design/improve the study as it evolved; SS advised on the design of the neuropsychological testing battery; FvP provided expert knowledge on occupation classification and the demographics of the 1910-1920 birth cohorts, HMH contributed substantive support for study set-up; MH helped with the study design and manages the Open Clinica database for data storage; PS contributed substantive support for the study and aided with obtaining necessary funding. All authors read and approved the final manuscript.

Funding This work was supported by Stichting Alzheimer Nederland (WE09.2014-03), Stichting Diorapthe (VSM $1404 \quad 14$ 02) and Stichting VUmc Fonds.

\section{Compliance with ethical standards}

Conflict of interest The authors declare that they have no conflict of interests.

Ethics approval and consent to participate The local Medical Ethical Committee has approved the 100-plus Study (registration number: 2016.440). All procedures performed in studies involving human 
participants were in accordance with the ethical standards of the institutional and/or national research committee and with the 1964 Helsinki declaration and its later amendments or comparable ethical standards.

Informed consent Informed consent was obtained from all individual participants included in the study.

Open Access This article is distributed under the terms of the Creative Commons Attribution 4.0 International License (http://creative commons.org/licenses/by/4.0/), which permits unrestricted use, distribution, and reproduction in any medium, provided you give appropriate credit to the original author(s) and the source, provide a link to the Creative Commons license, and indicate if changes were made.

\section{Box: Study rationale}

The design of an intervention for neurodegenerative diseases requires not only the understanding of the neurodegenerative processes involved, but also a deep comprehension of the processes that maintain cognitive health during ageing. Although increasing age is the strongest predictive factor for cognitive decline and dementia, some people live to be over 110 years in great mental health. A Dutch woman, Hendrikje van AndelSchipper (1890-2005), reached the age of 115 with full cognitive abilities [3] and showed that it is possible to reach extreme ages without any symptoms of cognitive decline. Her remarkable case became the source of inspiration for the initiation of the 100-plus Study at the Alzheimer Center Amsterdam in 2013. To investigate the physiology of her extended cognitive health, it is necessary to compare her clinical characteristics with those from other individuals with the same extraordinary combination of phenotypes: extremely old and cognitively healthy. Below, we provide a rationale for researching protective factors against cognitive decline in cognitively healthy centenarians, based on the mortality rate and dementia incidence in their birth cohort during its process of aging.

The number of centenarians in the Netherlands is growing quickly: on January 1st 2013 there were 1940 centenarians in the Netherlands, which grew to 2225 centenarians on January 1st 2017, and this number is expected to rise to 5000 by 2035 [54]. Of the individuals born between 1910 and 1915, approximately $1: 160(0.6 \%)$ have reached ages $\geq 100$ years [72]. Since $25-30 \%$ of all centenarians are estimated to be free of symptoms of cognitive decline [74-76], becoming a centenarian with retained cognitive health was reserved for only $0.2-0.3 \%$ of the 1910 and 1915 birth generation.

Almost all participants of the 100-plus Study cohort were born in the Netherlands just before or during WWI (1914 and 1917), in which the Netherlands was neutral. The 20th century in the Netherlands was further characterized by a depression in the thirties, WWII between 1940 and 1945, a post-war period typified by a rebuilding phase in the 1950s and a continuous increase in prosperity, health care improvements and technological developments. According to the Human Mortality Database [72] males born in the Netherlands between 1910 and 1915 had a mean lifespan of 58.7 years and females had a mean lifespan of 66.1 years.

Here we describe the 1910-1915 birth cohort by their mortality rates and dementia incidence from birth to $>100$ years (BoxFigure). For this, we prefer presenting the instant mortality rate over the mortality percentage, because, while estimates are similar at younger ages, the mortality percentage underestimates the mortality at extreme ages (for further explanation see Mortality estimations in ESM.pdf). For ages 0-60 years, we represent mortality rate by age from individuals born in 1912, and for ages $>60$ years we represent mortality rates using combined statistics from the 1910-1915 birth cohorts.

(A) In 1912, 170,000 babies were born, and they were exposed to a mortality rate of close to 0.10 deaths life-year $(\sim 10 \%$ per annual-year) during their first year of life, reflecting prevalent childhood diseases. (B) In 1918, the Spanish Flu made $>40,000$ casualties in the Netherlands [77], which was especially lethal among 20-40 year olds [78]. The Spanish Flu increased mortality among the 1912-born six-year olds by twofold. (C) At age 10, most childhood diseases were overcome and the mortality rate reached a stable $\sim 0.001-0.002$ deaths per life-year $(\sim 0.10-0.20 \%$ per annual-year), caused by incidental deaths (i.e. fatal accidents, drowning etc. (D) When the 1912 birth cohort was 28 years, the onset of WWII in 1940 led to a peak in male mortality. (E) The ensuing Hunger Winter in 1945 led to a second mortality peak when the 1912 birth cohort was 33 years old, more so in males than in females. $(\mathbf{F})$ When the cohort was 40 years old, the mortality resulting from natural decline rose above the rate of incidental deaths, and increased in the log scale according to Gompertz Law (1825) [79]. (G) During natural decline of the 1912 birth cohort, the males had a higher mortality rate than females, and this mortality gender gap ultimately resulted in a 1:7 male/female ratio at age 100 [54]. Approximately $70 \%$ of the mortality gender gap in these cohorts can be explained by the difference in smoking behavior between males and females [80]: an estimated $91 \%$ of all males born in 1912 smoked while only $30 \%$ of the females smoked, which ultimately led to a relative increased incidence of fatal smoking-related diseases in males. The remainder of the mortality gender gap may be explained by biological or environmental differences between males and females [81]. (H) At 100 years old, the 1912 cohort has reduced to \pm 1000 persons and the instant mortality rate for both males and females is at 0.5 deaths per life-year (which translates to a mortality percentage of $\sim 40 \%$ per annualyear).

(I) Individuals from the 1910-1915 birth cohorts were exposed to an increasing incidence of overall dementia from age 60 years onwards, of which the greatest proportion was (J) Alzheimer's Dementia (AD) [1]. At approximately 100 years, the instant incidence of dementia reaches 0.5 cases per dementia-free year, which translates to a dementia proportion of $\sim 40 \%$ per annual-year. At this age, the dementia incidence surpasses the mortality rate per year, suggesting that after turning 100 years, a centenarian is exposed to greater odds of developing dementia than to die [6]. $\left(\mathbf{K}_{\mathbf{1}}\right)$ If dementia incidence after 100 years continues to increase exponentially, following the Gompertz law of natural decline [79], then a conservative estimation of dementia incidence (by concentrating mortality on incident dementia cases) suggests that all individuals who reach 108-110 years would have to be demented. $\left(\mathbf{K}_{\mathbf{2}}\right)$ In contrast, reports of individuals who are older than 110 years indicate that the majority of such individuals has, in fact, retained their cognitive health [3-5]. Therefore, it is likely that the incidence of dementia decelerates or even declines at extreme ages [6]. Although the slope of the incidence rate suggested by Corrada 
et al. (red dots in Box-Figure) is slightly smaller compared to the extrapolated incidence (dashed line), there currently is no clear evidence for this deceleration between 90 and 100 years $[2,82]$, it is most likely that this deceleration becomes evident somewhere after 100 years. This is consistent with findings in super-centenarians by Andersen et al. [5], who demonstrated the progressive compression of both disability and morbidity (in 6 diseases including dementia) with survival beyond 100 years. Furthermore, in a recent study based on data from 3836 centenarians in Italy, Barbi et al. found that mortality decelerates, and even plateaus, above age 105 [83]. Together, this suggests that factors that preserve (cognitive) health may be progressively enriched for during healthy aging [7], providing a window of opportunity to search for such protective factors in a population of healthy (super-)centenarians.

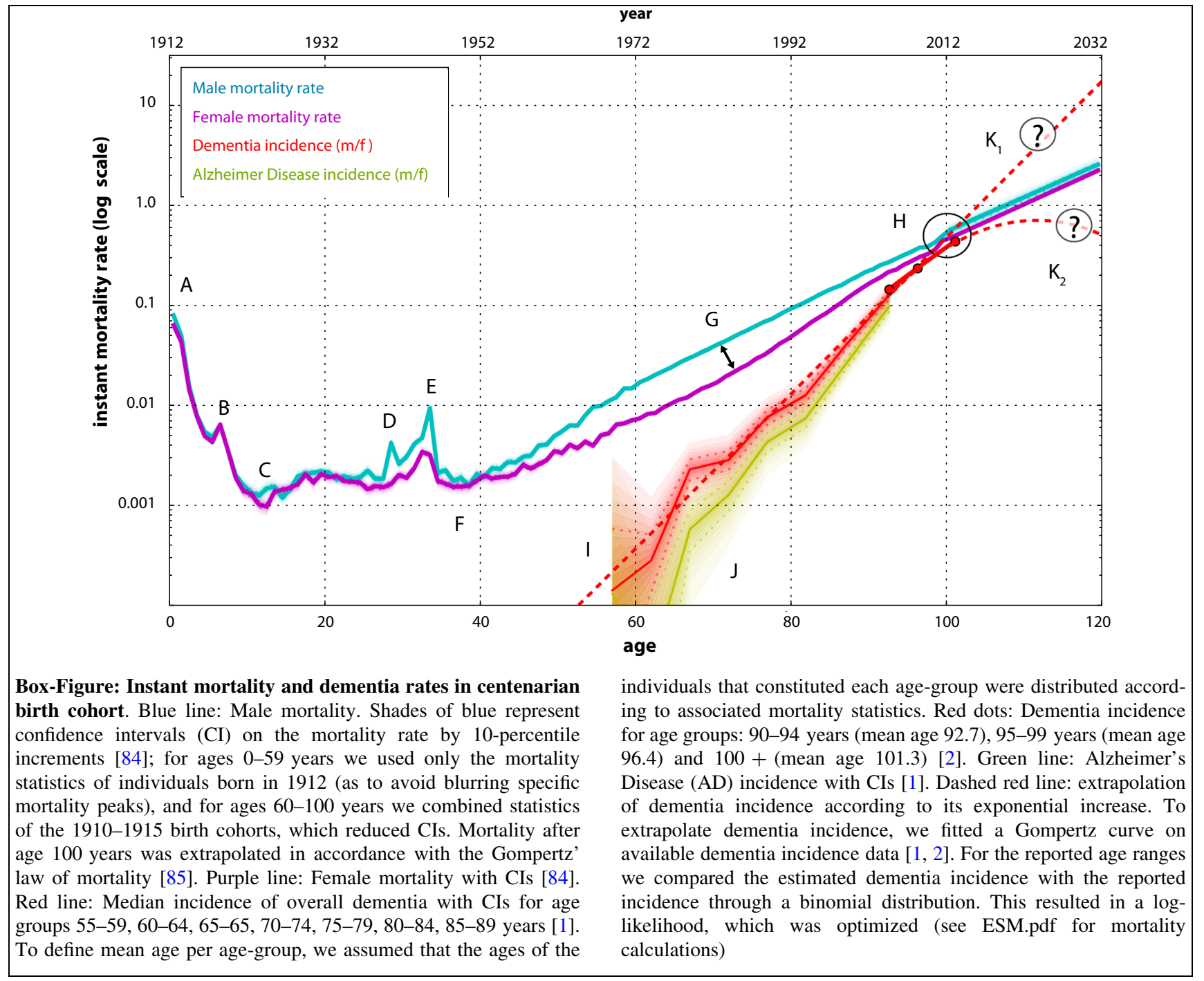




\section{References}

1. Lobo A, Lopez-Anton R, Santabarbara J, de-la-Camara C, Ventura T, Quintanilla MA, et al. Incidence and lifetime risk of dementia and Alzheimer's disease in a Southern European population. Acta Psychiatr Scand. 2011;124(5):372-83. https:// doi.org/10.1111/j.1600-0447.2011.01754.x.

2. Corrada MM, Brookmeyer R, Paganini-Hill A, Berlau D, Kawas $\mathrm{CH}$. Dementia incidence continues to increase with age in the oldest old: the $90+$ study. Ann Neurol. 2010;67(1):114-21. https://doi.org/10.1002/ana.21915.

3. den Dunnen WF, Brouwer WH, Bijlard E, Kamphuis J, van Linschoten K, Eggens-Meijer E, et al. No disease in the brain of a 115-year-old woman. Neurobiol Aging. 2008;29(8):1127-32. https://doi.org/10.1016/j.neurobiolaging.2008.04.010.

4. Jeune B, Robine J-M, Young R, Desjardins B, Skytthe A, Vaupel JW. Jeanne Calment and her successors. Biographical notes on the longest living humans. In: Maier H, Gampe J, Jeune B, Robine J-M, Vaupel JW, editors. Supercentenarians. Berlin, Heidelberg: Springer; 2010. p. 285-323.

5. Andersen SL, Sebastiani P, Dworkis DA, Feldman L, Perls TT. Health span approximates life span among many supercentenarians: compression of morbidity at the approximate limit of life span. J Gerontol Ser A: Biol Sci Med Sci. 2012;67A(4):395-405. https://doi.org/10.1093/gerona/glr223.

6. Robine JM, Jagger C. What do we know about the cognitive status of supercentenarians? In: Christen Y, editor. Research and perspectives in longevity; longevity and frailty. Berlin: Springer; 2003. p. $145-52$.

7. Barzilai N, Atzmon G, Derby CA, Bauman JM, Lipton RB. A genotype of exceptional longevity is associated with preservation of cognitive function. Neurology. 2006;67(12):2170-5. https://doi.org/10.1212/01.wnl.0000249116.50854.65.

8. Barral S, Cosentino S, Costa R, Andersen SL, Christensen K, Eckfeldt $\mathrm{JH}$, et al. Exceptional memory performance in the Long Life Family Study. Neurobiol Aging. 2013;34(11):2445-8. https://doi.org/10.1016/j.neurobiolaging.2013.05.002.

9. Cosentino S, Schupf N, Christensen K, Andersen SL, Newman A, Mayeux R. Reduced prevalence of cognitive impairment in families with exceptional longevity. JAMA Neurol. 2013;70(7):867-74. https://doi.org/10.1001/jamaneurol.2013. 1959.

10. Haworth CM, Wright MJ, Martin NW, Martin NG, Boomsma DI, Bartels M, et al. A twin study of the genetics of high cognitive ability selected from 11,000 twin pairs in six studies from four countries. Behav Genet. 2009;39(4):359-70. https://doi.org/ 10.1007/s10519-009-9262-3.

11. Petrill SA, Saudino K, Cherny SS, Emde RN, Fulker DW, Hewitt JK, et al. Exploring the genetic and environmental etiology of high general cognitive ability in fourteen- to thirty-sixmonth-old twins. Child Dev. 1998;69(1):68-74.

12. Petrill SA, Kovas Y, Hart SA, Thompson LA, Plomin R. The genetic and environmental etiology of high math performance in 10-year-old twins. Behav Genet. 2009;39(4):371-9. https://doi. org/10.1007/s10519-009-9258-z.

13. Plomin R, Haworth CM. Genetics of high cognitive abilities. Behav Genet. 2009;39(4):347-9. https://doi.org/10.1007/ s10519-009-9277-9.

14. Perls TT, Wilmoth J, Levenson R, Drinkwater M, Cohen M, Bogan $\mathrm{H}$, et al. Life-long sustained mortality advantage of siblings of centenarians. Proc Natl Acad Sci USA. 2002;99(12):8442-7. https://doi.org/10.1073/pnas.122587599.

15. Adams ER, Nolan VG, Andersen SL, Perls TT, Terry DF. Centenarian offspring: start healthier and stay healthier. J Am
Geriatr Soc. 2008;56(11):2089-92. https://doi.org/10.1111/j. 1532-5415.2008.01949.x.

16. Mostafavi H, Berisa T, Day FR, Perry JRB, Przeworski M, Pickrell JK. Identifying genetic variants that affect viability in large cohorts. PLoS Biol. 2017;15(9):e2002458. https://doi.org/ 10.1371/journal.pbio.2002458.

17. Sebastiani P, Andersen SL, McIntosh AI, Nussbaum L, Stevenson MD, Pierce L, et al. Familial risk for exceptional longevity. NAAJ. 2016;20(1):57-64. https://doi.org/10.1080/ 10920277.2015.1061946.

18. Harper AR, Nayee S, Topol EJ. Protective alleles and modifier variants in human health and disease. Nat Rev Genet. 2015;16(12):689-701. https://doi.org/10.1038/nrg4017.

19. Bucci L, Ostan R, Cevenini E, Pini E, Scurti M, Vitale G, et al. Centenarians' offspring as a model of healthy aging: a reappraisal of the data on Italian subjects and a comprehensive overview. Aging (Albany NY). 2016;8(3):510-9. https://doi.org/ 10.18632/aging.100912.

20. Atzmon G, Schechter C, Greiner W, Davidson D, Rennert G, Barzilai N. Clinical phenotype of families with longevity. J Am Geriatr Soc. 2004;52(2):274-7.

21. Silverman JM, Smith CJ, Marin DB, Birstein S, Mare M, Mohs $\mathrm{RC}$, et al. Identifying families with likely genetic protective factors against Alzheimer disease. Am J Hum Genet. 1999;64(3):832-8. https://doi.org/10.1086/302280.

22. Liu JZ, Erlich Y, Pickrell JK. Case-control association mapping by proxy using family history of disease. Nat Genet. 2017;49(3):325-31. https://doi.org/10.1038/ng.3766.

23. Jansen I, Savage J, Watanabe K, Bryois J, Williams D, Steinberg $S$ et al. Genetic meta-analysis identifies 10 novel loci and functional pathways for Alzheimer's disease risk. bioRxiv. 2018 (prepublication). https://doi.org/10.1101/258533.

24. Marioni RE, Harris SE, Zhang Q, McRae AF, Hagenaars SP, Hill WD, et al. GWAS on family history of Alzheimer's disease. Transl Psychiatry. 2018. https://doi.org/10.1038/s41398-0180150-6.

25. Bucci L, Ostan R, Cevenini E, Pini E, Scurti M, Vitale G, et al. Centenarians' offspring as a model of healthy aging: a reappraisal of the data on Italian subjects and a comprehensive overview. Aging. 2016;8(3):510-9. https://doi.org/10.18632/ aging. 100912.

26. Folstein MF, Folstein SE, McHugh PR. "Mini-mental state". A practical method for grading the cognitive state of patients for the clinician. J Psychiatr Res. 1975;12(3):189-98.

27. Mahoney FI, Barthel DW. Functional evaluation: the Barthel Index. Md State Med J. 1965;14:61-5.

28. Buysse DJ, Reynolds CF III, Monk TH, Berman SR, Kupfer DJ. The Pittsburgh Sleep Quality Index: a new instrument for psychiatric practice and research. Psychiatry Res. 1989;28(2):193-213.

29. Yesavage JA, Sheikh JI. 9/Geriatric Depression Scale (GDS). Clin Gerontol. 1986;5(1-2):165-73. https://doi.org/10.1300/ J018v05n01_09.

30. Jorm AF, Jacomb PA. The Informant Questionnaire on Cognitive Decline in the Elderly (IQCODE): socio-demographic correlates, reliability, validity and some norms. Psychol Med. 1989;19(4):1015-22.

31. de Jonghe JF, Schmand B, Ooms ME, Ribbe MW. Abbreviated form of the Informant Questionnaire on cognitive decline in the elderly. Tijdschr Gerontol Geriatr. 1997;28(5):224-9.

32. UNESCO. International Standard Classification of Education 1997. http://www.unesco.org/education/information/nfsunesco/ doc/isced_1997.htm. 1997.

33. Vliegen JM, de Jong U, Wesselingh AA, van der Kley P, CBS, SISWO. Education in the Netherlands. Monografiëën 
volkstelling 1971. The Hague s-Gravenhage: Centraal Bureau voor de Statistiek: Staatsuitgeverij; 1981.

34. Wilson R, Barnes L, Bennett D. Assessment of lifetime participation in cognitively stimulating activities. J Clin Exp Neuropsychol. 2003;25(5):634-42. https://doi.org/10.1076/jcen.25. 5.634.14572.

35. Wilson RS, Barnes LL, Krueger KR, Hoganson G, Bienias JL, Bennett DA. Early and late life cognitive activity and cognitive systems in old age. J Int Neuropsychol Soc. 2005;11(4):400-7.

36. Netherlands Brain Bank. http://www.brainbank.nl/.

37. Ravid R, Swaab DF. The Netherlands brain bank-a clinicopathological link in aging and dementia research. J Neural Transm Suppl. 1993;39:143-53.

38. Open Clinica. Copyright $@$ C OpenClinica LLC and collaborators, Waltham, MA, USA. http://www.OpenClinica.com.

39. Statistics Netherlands. 14e Algemene Volkstelling annex woningtelling 28 februari 1971. The Hague: Centraal Bureau voor de Statistiek; 1980. p. 40.

40. Mandemakers K. Historical sample of the Netherlands HSN. Hist Soc Res. 2001;26(4):179-90.

41. Gadourek I. Riskante gewoonten en zorg voor eigen welzijn (Hazardous habits and human well-being). Groningen: J.B. Wolters; 1963.

42. STIVORO. Trendpublicatie percentage rokers. Percentage rokers in de Nederlandse bevolking 1958 - 2012 (Arranged by GE Nagelhout) 2013.

43. Van Poppel F, Reher D, Sanz-Gimeno A, Sanchez-Dominguez M, Beekink E. Mortality decline and reproductive change during the Dutch demographic transition. Demogr Res. 2012;27:299-338. https://doi.org/10.4054/DemRes.2012.27.11.

44. Dykstra PA. Childless old age. In: Uhlenberg P, editor. International handbook of population aging. Berlin: Springer; 2009. p. $671-90$.

45. Huisman M, Poppelaars J, van der Horst M, Beekman AT, Brug J, van Tilburg TG, et al. Cohort profile: the Longitudinal Aging Study Amsterdam. Int J Epidemiol. 2011;40(4):868-76. https:// doi.org/10.1093/ije/dyq219.

46. Miller LS, Mitchell MB, Woodard JL, Davey A, Martin P, Poon $\mathrm{LW}$, et al. Cognitive performance in centenarians and the oldest old: norms from the Georgia Centenarian Study. Aging Neuropsychol Cogn. 2010;17(5):575-90. https://doi.org/10.1080/ 13825585.2010.481355.

47. Bauco C, Borriello C, Cinti AM, Martella S, Zannino G, Rossetti C, et al. Correlation between MMSE performance, age and education in centenarians. Arch Gerontol Geriatr. 1998;26:23-6. https://doi.org/10.1016/s0167-4943(98)80004-6.

48. Baldelli MV, Salvioli G, Neri M, Pradelli JM. A survey of a centenarian population in Italy, focusing on self-sufficiency and cognition. Arch Gerontol Geriatr. 1996;22(Suppl 1):345-54. https://doi.org/10.1016/0167-4943(96)86960-3.

49. Holtsberg PA, Poon LW, Noble CA, Martin P. Mini-Mental State Exam status of community-dwelling cognitively intact centenarians. Int Psychogeriatr. 1995;7(3):417-27.

50. Inagaki H, Gondo Y, Hirose N, Masui Y, Kitagawa K, Arai Y, et al. Cognitive function in Japanese centenarians according to the mini-mental state examination. Dement Geriatr Cogn Disord. 2009;28(1):6-12. https://doi.org/10.1159/000228713.

51. Central Bureau of Statistics: Prognosis period-life expectancy; gender and age, 2014-2060 [database on the Internet]. Netherlands Statistics. 2017. http://statline.cbs.nl/Statweb/publication/ $? \mathrm{DM}=\mathrm{SLNL} \& \mathrm{PA}=82690 \mathrm{ned} \& \mathrm{D} 1=0 \mathrm{DD} 2=\mathrm{a} \& \mathrm{D} 3=\mathrm{a} \& \mathrm{D} 4=$ $0,16,1 \& \mathrm{VW}=\mathrm{T}$. Accessed 29 Aug 2017.

52. Skoog J, Backman K, Ribbe M, Falk H, Gudmundsson P, Thorvaldsson V, et al. A Longitudinal Study of the mini-mental state examination in Late Nonagenarians and Its Relationship with Dementia, Mortality, and Education. J Am Geriatr Soc. 2017;65(6):1296-300. https://doi.org/10.1111/jgs.14871.

53. Mossakowska M, Broczek K, Wieczorowska-Tobis K, KlichRaczka A, Jonas M, Pawlik-Pachucka E, et al. Cognitive performance and functional status are the major factors predicting survival of centenarians in Poland. J Gerontol Ser A: Biol Sci Med Sci. 2014;69(10):1269-75. https://doi.org/10.1093/gerona/ glu003.

54. Centraal Bureau voor de Statistiek. Aantal 100-plussers verdubbeld in 20 jaar. In: Webmagazine CBS. 2017. https://www. cbs.nl/nl-nl/nieuws/2017/20/aantal-100-plussers-verdubbeld-in20-jaar.

55. Yang Z, Slavin MJ, Sachdev PS. Dementia in the oldest old. Nature reviews Neurology. 2013;9(7):382-93. https://doi.org/ 10.1038/nrneurol.2013.105.

56. Corrada MM, Brookmeyer R, Berlau D, Paganini-Hill A, Kawas $\mathrm{CH}$. Prevalence of dementia after age 90: results from the $90+$ study. Neurology. 2008;71(5):337-43. https://doi.org/10. 1212/01.wnl.0000310773.65918.cd.

57. Hazra NC, Dregan A, Jackson S, Gulliford MC. Differences in health at age 100 according to sex: population-based cohort study of centenarians using electronic health records. J Am Geriatr Soc. 2015;63(7):1331-7. https://doi.org/10.1111/jgs. 13484.

58. Pinn VW. Past and future: sex and gender in health research, the aging experience, and implications for musculoskeletal health. Orthop Clin N Am. 2006;37(4):513-21. https://doi.org/10.1016/ j.ocl.2006.09.006.

59. Wingard DL, Cohn BA, Kaplan GA, Cirillo PM, Cohen RD. Sex differentials in morbidity and mortality risks examined by age and cause in the same cohort. Am J Epidemiol. 1989;130(3):601-10.

60. Roman-Blas JA, Castaneda S, Largo R, Herrero-Beaumont G. Osteoarthritis associated with estrogen deficiency. Arthritis Res Ther. 2009;11(5):241. https://doi.org/10.1186/ar2791.

61. Garatachea N, Marin PJ, Santos-Lozano A, Sanchis-Gomar F, Emanuele E, Lucia A. The ApoE gene is related with exceptional longevity: a systematic review and meta-analysis. Rejuven Res. 2015;18(1):3-13. https://doi.org/10.1089/rej.2014. 1605.

62. Gerdes LU, Jeune B, Ranberg KA, Nybo H, Vaupel JW. Estimation of apolipoprotein $\mathrm{E}$ genotype-specific relative mortality risks from the distribution of genotypes in centenarians and middle-aged men: apolipoprotein E gene is a "frailty gene," not a "longevity gene". Genet Epidemiol. 2000;19(3):202-10. https://doi.org/10.1002/1098-2272(200010)19:3\%3c202:AIDGEPI2\%3e3.0.CO;2-Q.

63. Genin E, Hannequin D, Wallon D, Sleegers K, Hiltunen M, Combarros O, et al. APOE and Alzheimer disease: a major gene with semi-dominant inheritance. Mol Psychiatry. 2011;16(9):903-7. https://doi.org/10.1038/mp.2011.52.

64. Farrer LA, Cupples LA, Haines JL, Hyman B, Kukull WA, Mayeux R, et al. Effects of age, sex, and ethnicity on the association between apolipoprotein $\mathrm{E}$ genotype and Alzheimer disease. A meta-analysis. APOE and Alzheimer Disease Meta Analysis Consortium. JAMA. 1997;278(16):1349-56.

65. Garatachea N, Emanuele E, Calero M, Fuku N, Arai Y, Abe Y, et al. ApoE gene and exceptional longevity: insights from three independent cohorts. Exp Gerontol. 2014;53:16-23. https://doi. org/10.1016/j.exger.2014.02.004.

66. Kunst AE, Looman CW, Mackenbach JP. Socio-economic mortality differences in The Netherlands in 1950-1984: a regional study of cause-specific mortality. Soc Sci Med. 1990;31(2):141-52.

67. Fors S, Lennartsson C, Lundberg O. Childhood living conditions, socioeconomic position in adulthood, and cognition in 
later life: exploring the associations. J Gerontol Ser B: Psychol Sci Soc Sci. 2009;64(6):750-7. https://doi.org/10.1093/geronb/ gbp029.

68. Modig K, Talback M, Torssander J, Ahlbom A. Payback time? Influence of having children on mortality in old age. J Epidemiol Community Health. 2017;71(5):424-30. https://doi.org/10.1136/ jech-2016-207857.

69. Rajpathak SN, Liu Y, Ben-David O, Reddy S, Atzmon G, Crandall $\mathrm{J}$, et al. Lifestyle factors of people with exceptional longevity. J Am Geriatr Soc. 2011;59(8):1509-12. https://doi. org/10.1111/j.1532-5415.2011.03498.x.

70. Zainabadi K. A brief history of modern aging research. Exp Gerontol. 2018;104:35-42. https://doi.org/10.1016/j.exger.2018. 01.018 .

71. Scheltens P, Blennow K, Breteler MM, de Strooper B, Frisoni GB, Salloway S, et al. Alzheimer's disease. Lancet. 2016;388(10043):505-17. https://doi.org/10.1016/S01406736(15)01124-1.

72. CBS/HMD. Unpublished data from the NIDI mortality database provided by Ewa Tabeau (NIDI) (1850-1949); Central Bureau of Statistics 1949-onwards (Data obtained through the Human Mortality Database, http://www.mortality.org on 29-5-2017).

73. Poon LW, Woodard JL, Stephen Miller L, Green R, Gearing M, Davey $\mathrm{A}$, et al. Understanding dementia prevalence among centenarians. J Gerontol Ser A: Biol Sci Med Sci. 2012;67(4):358-65. https://doi.org/10.1093/gerona/glr250.

74. Kliegel M, Moor C, Rott C. Cognitive status and development in the oldest old: a longitudinal analysis from the Heidelberg Centenarian Study. Arch Gerontol Geriatr. 2004;39(2):143-56. https://doi.org/10.1016/j.archger.2004.02.004.

75. Andersen-Ranberg K, Vasegaard L, Jeune B. Dementia is not inevitable: a population-based study of Danish centenarians. J Gerontol Ser B: Psychol Sci Soc Sci. 2001;56(3):P152-9.

76. Calvert JF Jr, Hollander-Rodriguez J, Kaye J, Leahy M. Dementia-free survival among centenarians: an evidence-based review. J Gerontol Ser A: Biol Sci Med Sci. 2006;61(9):951-6.

77. Ansart S, Pelat C, Boelle PY, Carrat F, Flahault A, Valleron AJ. Mortality burden of the 1918-1919 influenza pandemic in Europe. Influenza Other Respir Viruses. 2009;3(3):99-106. https:// doi.org/10.1111/j.1750-2659.2009.00080.x.

78. Taubenberger JK, Morens DM. 1918 Influenza: the mother of all pandemics. Emerg Infect Dis. 2006;12(1):15-22. https://doi.org/ 10.3201/eid1201.050979.

79. Gompertz B. On the nature of the function expressive of the law of human mortality, and on a new mode of determining the value of life contingencies. Philos Trans $\mathrm{R}$ Soc Lond. 1825;115:513-83.

80. Janssen F, van Poppel FWA. Roken veroorzaakte vroeger grote verschillen in levensverwachting. DEMOS: Bulletin over Bevolking en Samenleving. 2016. p. 4-6.

81. Newman AB, Murabito JM. The epidemiology of longevity and exceptional survival. Epidemiol Rev. 2013;35:181-97. https:// doi.org/10.1093/epirev/mxs013.

82. James BD, Schneider JA. Increasing incidence of dementia in the oldest old: evidence and implications. Alzheimers Res Ther. 2010;2(3):9. https://doi.org/10.1186/alzrt32.

83. Barbi E, Lagona F, Marsili M, Vaupel JW, Wachter KW. The plateau of human mortality: demography of longevity pioneers. Science. 2018;360(6396):1459-61. https://doi.org/10.1126/sci ence.aat 3119 .

84. Central Bureau of Statistics: Life expectancy per birth cohort. [database on the Internet]. Netherlands Statistics. 2017. http:// statline.cbs.nl/Statweb/dome/?TH=26190\&PA= 80333NED\&LA=nl. Accessed 11 Aug 2015.
85. Gavrilov LA, Gavrilova NS. Mortality measurement at advanced ages: a study of the social security administration death master file. NAAJ. 2011;15(3):432-47.

86. Kok RM, Verhey FRJ. Gestandaardiseerde MMSE. Zeist: Altrecht GGZ; 2002.

87. Nelson HE, O'Connell A. Dementia: the estimation of premorbid intelligence levels using the New Adult Reading Test. Cortex. 1978;14(2):234-44.

88. Schmand B, Lindeboom J, van Harskamp F. Nederlandse leestest voor volwassenen. In: Bouma A, Mulder J, Lindeboom J, editors. Neuropsychologische Diagnostiek. Lisse: Swets \& Zeitlinger; 1992. p. A45-A52.

89. Schmand B, Bakker D, Saan R, Louman J. De Nederlandse Leestest voor Volwassenen: een maat voor het premorbide intelligentieniveau. Gerontologie en Geriatrie. 1991;22:15-9.

90. de Jager CA, Budge MM, Clarke R. Utility of TICS-M for the assessment of cognitive function in older adults. Int $\mathrm{J}$ Geriatr Psychiatry. 2003;18(4):318-24. https://doi.org/10.1002/gps.830.

91. Morris JC, Heyman A, Mohs RC, Hughes JP, van Belle G, Fillenbaum G, et al. The Consortium to Establish a Registry for Alzheimer's Disease (CERAD). Part I. Clinical and neuropsychological assessment of Alzheimer's disease. Neurology. 1989;39(9):1159-65.

92. Lindeboom J, Schmand B, Tulner L, Walstra G, Jonker C. Visual association test to detect early dementia of the Alzheimer type. J Neurol Neurosurg Psychiatry. 2002;73(2):126-33.

93. Wilson BA, Cockburn J, Baddeley AD. The Rivermead behavioural memory test. 2nd ed., rev., enl. and redesigned. ed. Reading: Thames Valley Test Company; 1991.

94. Wilson B, Cockburn J, Baddeley A, Hiorns R. The development and validation of a test battery for detecting and monitoring everyday memory problems. J Clin Exp Neuropsychol. 1989;11(6):855-70. https://doi.org/10.1080/01688638908400940.

95. Lindeboom J, Matto D. Digit series and Knox cubes as concentration tests for elderly subjects. Tijdschr Gerontol Geriatr. 1994;25(2):63-8.

96. Wechsler D. Wechsler adult intelligence scale-revised. San Antonio: Psychological Corporation; 1981.

97. Wechsler D. WAIS-III administration and scoring manual. San Antonio: Psychological Corporation; 1997.

98. Army Individual Test Battery. Manual of Directions and Scoring. War Department AGsO, editor. Washington, DC, USA; 1944.

99. Reitan RM. Validity of the Trail Making Test as an indicator of organic brain damage. Percept Mot Skills. 1958;8:271-6. https:// doi.org/10.2466/PMS.8.7.271-276.

100. Van der Elst W, Van Boxtel MP, Van Breukelen GJ, Jolles J. Normative data for the Animal, Profession and Letter M Naming verbal fluency tests for Dutch speaking participants and the effects of age, education, and sex. JINS. 2006;12(1):80-9. https://doi.org/10.1017/S1355617706060115.

101. Lezak MD, Howieson DB, Loring DW, Fischer JS. Neuropsychological assessment. Oxford University Press; 2004.

102. Schmand B, Groenink SC, van den Dungen M. Letter fluency: psychometric properties and Dutch normative data. Tijdschr Gerontol Geriatr. 2008;39(2):64-76.

103. Snijders J, Luteijn F, van der Ploeg F, Verhage F. Handleiding Groninger intelligentie test. Lisse: Swets \& Zeitlinger; 1983.

104. Benton AL, Hamsher KD. Multilingual aphasia examination. Iowa City: AJA Associates; 1989.

105. Krabbendam L, de Vugt ME, Derix MM, Jolles J. The behavioural assessment of the dysexecutive syndrome as a tool to assess executive functions in schizophrenia. Clin Neuropsychol. 1999;13(3):370-5. https://doi.org/10.1076/clin.13.3.370.1739.

106. Wilson BA, Evans JJ, Alderman N, Burgess PW, Emslie H. Behavioural assessment of the dysexecutive syndrome. In: 
Rabbitt P, editor. Theory and methodology of frontal and executive function. East Sussex: Psychology Press; 1997. p. 239-50.

107. Lindeboom J, Jonker C. Amsterdam dementia screening test, manual. Dutch: Amsterdamse Dementiescreeningtest, handleiding Lisse, The Netherlands; 1989.

108. Luteijn F, Van der Ploeg FA. Groninger Intelligentie Test: Handleiding [Groninger Intelligence Test: Manual]. Lisse: Swets, Zeitlinger BV; 1983.

109. Roth M, Tym E, Mountjoy CQ, Huppert FA, Hendrie H, Verma $\mathrm{S}$, et al. CAMDEX. A standardised instrument for the diagnosis of mental disorder in the elderly with special reference to the early detection of dementia. Br J Psychiatry J Ment Sci. 1986;149:698-709.

110. Roth M, Huppert FA, Mountjoy CQ, Tym E. CAMDEX-R Boxed Set: The Revised Cambridge Examination for Mental Disorders of the Elderly. Cambridge University Press; 1998.

111. Shulman KI, Pushkar Gold D, Cohen CA, Zucchero CA. Clockdrawing and dementia in the community: a longitudinal study. Int J Geriatr Psychiatry. 1993;8(6):487-96. https://doi.org/10. 1002/gps.930080606.
112. Shulman KI. Clock-drawing: is it the ideal cognitive screening test? Int J Geriatr Psychiatry. 2000;15(6):548-61.

113. Warrington EK, James M. The visual object and space battery perception. 1991.

114. Collin C, Wade DT, Davies S, Horne V. The Barthel ADL Index: a reliability study. Int Disabil Stud. 1988;10(2):61-3.

115. de Haan R, Limburg M, Schuling J, Broeshart J, Jonkers L, van Zuylen P. Clinimetric evaluation of the Barthel Index, a measure of limitations in dailly activities. Ned Tijdschr Geneeskd. 1993;137(18):917-21.

116. Post MW, van Asbeck FW, van Dijk AJ, Schrijvers AJ. Dutch interview version of the Barthel Index evaluated in patients with spinal cord injuries. Ned Tijdschr Geneeskd. 1995;139(27):1376-80.

117. Kahle-Wrobleski K, Corrada MM, Li B, Kawas CH. Sensitivity and specificity of the mini-mental state examination for identifying dementia in the oldest-old: the $90+$ study. J Am Geriatr Soc. 2007;55(2):284-9. https://doi.org/10.1111/j.1532-5415. 2007.01049.x. 